\title{
23. JURASSIC TO PALEOCENE PALEOLATITUDES OF THE PACIFIC PLATE DERIVED FROM THE PALEOMAGNETISM OF THE SEDIMENTARY SEQUENCES AT SITES 800, 801, AND 802 ${ }^{1}$
}

\author{
Maureen B. Steiner ${ }^{2}$ and Brian P. Wallick ${ }^{3}$
}

\begin{abstract}
The remanent magnetizations contained in the three sedimentary sections recovered by Leg 129 are of relatively strong intensities and have notably minor amounts of secondary magnetization. Both alternating field and thermal demagnetization techniques readily separate magnetization components, resulting in remanent directions that are exceptionally single component at the higher stages of demagnetization. In all types of lithology, the magnetization is carried by a mineral with blocking temperatures below $570^{\circ} \mathrm{C}$, presumably a member of the titanomagnetite series. The resulting inclinations are generally very consistent among samples from the same time periods. Substantially incomplete recovery at each site, a result of the disruptive effect on coring and recovery in mixed sediments of chert interspersed with calcareous and clayey sediments, prevented reconstruction of complete magnetostratigraphic records from these sedimentary sequences. The inclination records from the three holes provide a relatively continuous history of the paleolatitudinal motion of the oldest portion of the Pacific plate from the Campanian stage of the Late Cretaceous to the Callovian/Bathonian boundary of the Middle Jurassic; data of somewhat lessor quality were also obtained for the early Miocene through Paleocene. All data indicate that this embryonic portion of the Pacific plate was in southern paleolatitudes from the Middle Jurassic to the Late Cretaceous and probably crossed the equator between the Turonian and the late Paleocene. These data suggest that during the Late Jurassic and Cretaceous, the plate was never too far from the equator, varying between about $20^{\circ} \mathrm{S}$ and equatorial latitudes. If the phenomenon of inclination error is operative in these sediments, as has been claimed for many oceanic sediments, then obviously the plate was at higher southern latitudes than indicated by these data. However, qualitative estimates of paleolatitudes from nannofossil abundances (Erba, this volume) indicate paleolatitudes quite similar to those calculated from the remanent inclinations. Moreover, calculations of expected inclination error from published analyses result in paleolatitudes much farther south than predicted by seamount paleopoles or magnetic anomaly skewness. Therefore, the paleolatitudes determined from the inclinations recorded in the sediments of this study may represent approximately the true paleopositions of the Pacific plate.
\end{abstract}

\section{INTRODUCTION}

The sedimentary section cored at the three sites of Ocean Drilling Program (ODP) Leg 129 extends from the Campanian stage of the Late Cretaceous to the Bathonian/Callovian boundary of the Middle Jurassic. Holes $800 \mathrm{~A}, 801 \mathrm{~A}, 801 \mathrm{~B}$, and $802 \mathrm{~A}$ all contained sedimentary sequences spanning the Campanian through a portion of the Lower Cretaceous Aptian stages. Recovery at Hole 800A extended further, through the Berriasian, at which point intrusive dolerite was encountered. Beyond the Aptian stage, recovery at Hole 801B contained material extending through the entire Upper Jurassic to sediment as old as Bathonian-Callovian age and oceanic basement representing the Jurassic Quiet Zone of the marine magnetic anomaly pattern. Additionally, sediments younger than Campanian age, particularly a sequence of Paleocene through Miocene age, were recovered at Hole $802 \mathrm{~A}$.

The three sites are broadly spaced over the oldest portion of the Pacific plate (Fig. 1). The sedimentary sections of these holes were sampled for paleomagnetic measurements at an interval of between 0.5 to $1.5 \mathrm{~m}$, depending on the recovery in any particular interval. The samples were taken principally for the determination of the paleolatitudinal position of the Pacific plate from the time of the Jurassic Quiet Zone, Mid-Jurassic, through the Late Cretaceous.

\footnotetext{
' Larson, R. L., Lancelot, Y., et al., 1992. Proc. ODP, Sci. Results, 129: College Station, TX (Ocean Drilling Program).

${ }^{2}$ Dept. of Geology and Geophysics, University of Wyoming, Laramie, WY 82071. U.S.A.

${ }^{3}$ Dept. of Earth \& Atmospheric Sciences, Purdue University, West Lafayette, IN 47907. U.S.A.
}

\section{SITE 800}

Paleomagnetic samples were taken from the Campanian portion of the recovered section (Core 129-800A-6R) through the Valanginian (Core $800 \mathrm{~A}-55 \mathrm{R}$ ); the recovery of the basal Berriasian sediment in contact with intrusive basalt was too meager to sample. Samples were taken from every core except Cores $800 \mathrm{~A}-42 \mathrm{R}$ and $800 \mathrm{~A}-46 \mathrm{R}$; these two were not sampled because of their position within extremely thick turbidite sequences in which individual cores represent very little geologic time. Recovery frequently limited the number of paleomagnetic samples that could be taken within a cored interval, but minicores (1-in.-long, 1-in.-diameter cylinders) or portions thereof were taken as continuously as possible; that is, one or two per core-section ( 1 to 2 per 1.5 meters). A total of 210 samples were taken from the sediments of this site.

Natural remanent magnetization (NRM) was measured for all samples. Most of the core displays negative inclinations, and demagnetization behavior suggestive of normal polarity (explained below). The inference of a dominance of normal polarity is consistent with the biostratigraphic age (Shipboard Scientific Party, 1990a) which places most of the core within the Cretaceous Normal Polarity Superchron. As these normal polarity samples have negative inclinations, they indicate that the site was in the Southern Hemisphere during this time.

Inclinations from the entire hole generally ranged from horizontal to $-30^{\circ}$. The present and axial field inclinations for this site, located at $21.9^{\circ} \mathrm{N} 152.3^{\circ} \mathrm{E}$ (Fig. 1), are respectively $39^{\circ}$ and $27^{\circ}$. NRM intensities of magnetization varied according to lithology. Samples from the highest lithologic type sampled (brown chert and porcellanite, Unit II) typically had intensities of $2 \times 10^{-1} \mathrm{~A} / \mathrm{m}$; those from Unit III, gray radiolarian chert and limestone, averaged $1 \times 10^{-1} \mathrm{~A} / \mathrm{m}$; the redeposited volcaniclastics comprising Unit IV had NRM intensities 


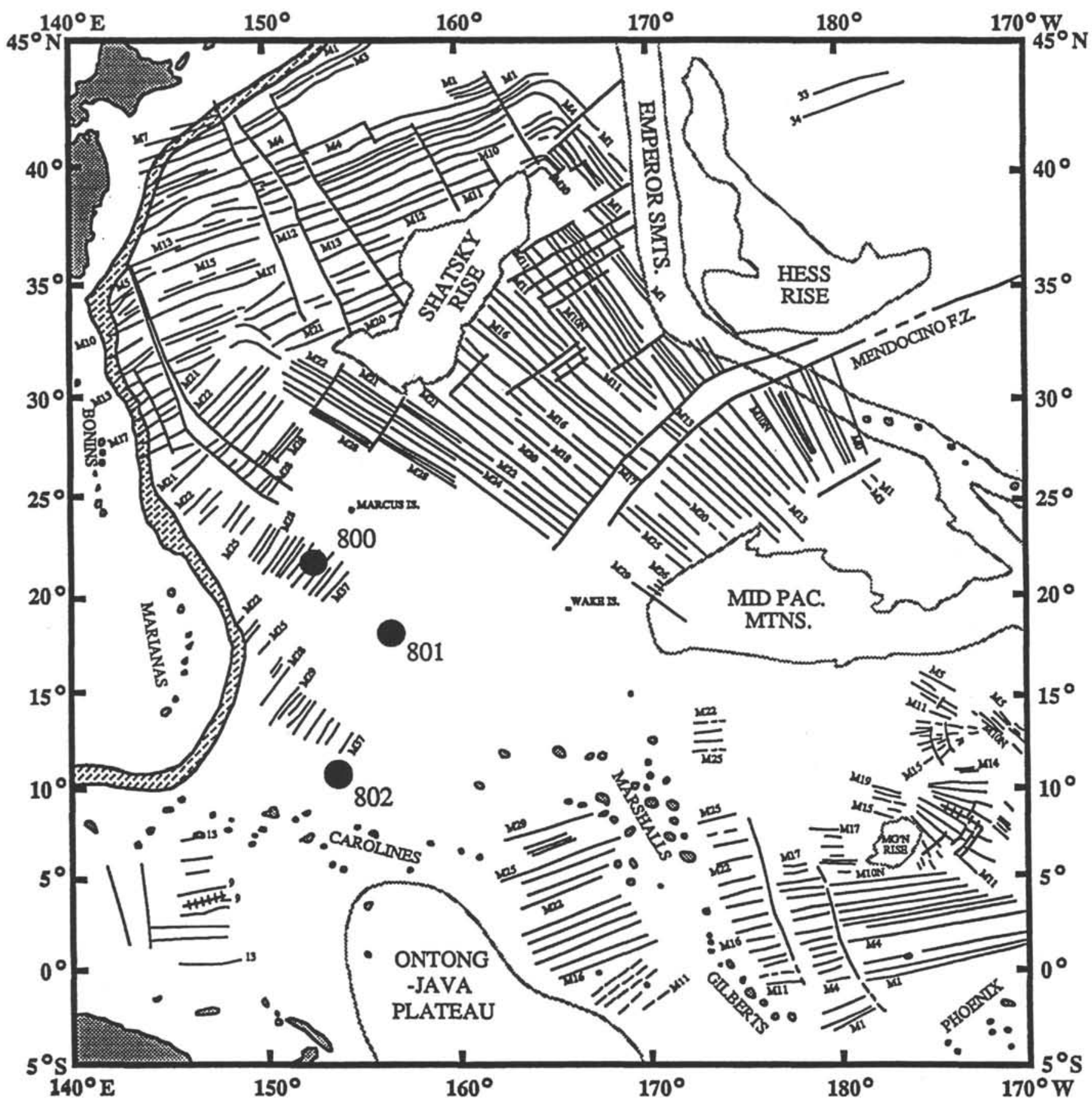

Figure 1. Location of Sites 800,801 , and 802 shown with the marine magnetic anomaly pattern for this part of the Pacific plate (from Larson and Sager, this volume).

that were typically $2 \mathrm{~A} / \mathrm{m}$ in the upper half of the section and $8 \times 10^{-1}$ $\mathrm{A} / \mathrm{m}$ in the lower part (with the change occurring within Core $800 \mathrm{~A}$ $39 \mathrm{R}$ ); the intensities of the clay and radiolarite (Unit V) averaged about $6 \times 10^{-1} \mathrm{~A} / \mathrm{m}$.

Representative pairs of samples from the same stratigraphic horizon were demagnetized, one by alternating field (AF), and the other by thermal treatment. AF and thermal demagnetization gave very similar results on most samples. The same stable end-point direction generally resulted from both demagnetization techniques, and both reduced the magnetization to the same intensity level after $60 \mathrm{mT}$ and $570^{\circ} \mathrm{C}$ respectively. These characteristics suggest that remanence carrier is a mineral composition in the Ti-magnetite series. Thermal demagnetization allowed the remanent magnetization to be reduced to almost zero, whereas AF treatment was limited to $60 \mathrm{mT}$, above which anhysteretic magnetizations were introduced by the equipment. Moreover, thermal demagnetization sometimes resulted in linear demagnetization trends in the same samples in which AF produced erratic behavior. The slightly better results with thermal treatment and the presence of red sediments in the lower part of the section (Unit V) induced us to use thermal demagnetization to determine the characteristic magnetization for all samples. All samples were thermally demagnetized in 11 to 13 steps, which included $130^{\circ}$, $170^{\circ}, 200^{\circ}, 250^{\circ}, 300^{\circ}, 350^{\circ}, 400^{\circ}, 450^{\circ}, 500^{\circ}, 540^{\circ}, 550^{\circ}, 563^{\circ}$, $566^{\circ}, 600^{\circ}$, and $650^{\circ} \mathrm{C}$. 
The magnetic vectors contained in the samples of this hole were readily separated by thermal demagnetization. For at least $80 \%$ of the samples, the blocking temperature spectra do not overlap significantly. Thermal demagnetization to temperatures above either $250^{\circ} \mathrm{C}$, but more commonly above $350^{\circ} \mathrm{C}$, for all types of lithology except the red-brown clay and radiolarites of Unit $\mathrm{V}$ caused sample magnetizations to decay linearly to the origin of orthogonal axes plots. Figures $2 \mathrm{~A}$ through $2 \mathrm{C}$ show typical samples of Units II through IV. For all lithology types except that of Unit V, most of the remanent magnetization is lost above about $550^{\circ} \mathrm{C}$; at higher temperatures, directions become erratic and intensities quite weak, as illustrated by Figure $2 \mathrm{~B}$. The magnetization vectors most commonly removed during demagnetization are the present or axial field direction, based on the values of the inclinations of the subtracted vectors, and for samples from lithologic Units III and IV, a horizontal vector of very nearly zero inclination. Declination of the removed horizontal vector is the same as that of the characteristic normal magnetization of these samples; a typical example of a sample containing this vector is illustrated in Figure 2C. The horizontal vector is removed usually at low, but sometimes at higher, temperatures throughout the blocking temperature spectrum between about $150^{\circ} \mathrm{C}$ and $400^{\circ} \mathrm{C}$; it is always eliminated by heating above $400^{\circ} \mathrm{C}$.

In contrast to the samples above them, the samples from lithologic Unit V exhibit both normal and reversed polarities, consistent with their Early Cretaceous age. Representative examples of both polarities are shown in Figures 2D and 2E. The blocking temperature spectra of the characteristic and secondary magnetizations generally overlap below $500^{\circ} \mathrm{C}$. At temperatures between $500^{\circ}-575^{\circ} \mathrm{C}$ the remanent magnetization decays univectorially toward the origin of orthogonal axes plots. As with the higher lithologic units, the same two secondary magnetizations appear to be removed by demagnetization. The normal polarity of the near-horizontal vector is well illustrated in this unit; its addition to the two polarities of these samples demonstrates that its declination is quite close to that of the normal characteristic magnetization of this unit and antipodal to the reversed magnetizations.

The characteristic direction for each sample from this hole was determined by least-squares calculation of the direction of the line best fitting the linear portion of the demagnetization path directed toward the origin (Kirschvink, 1980). For lithologic Units II through IV, this linear trend usually involved the directions from the $350^{\circ}$ to $500^{\circ} \mathrm{C}$ temperature steps. Univectorial trends for Unit V generally encompassed the directions of the $500^{\circ}$ to $568^{\circ} \mathrm{C}$ steps. Samples that did not display trends toward the origin usually nevertheless displayed linear trends in their demagnetization paths above $250^{\circ} \mathrm{C}$ and lines were fit to these; these samples were given designations indicating their directions to be less reliable. The sample inclinations and intensities thus calculated are shown in stratigraphic sequence in Figure 3.

Polarity interpretations for each sample were similarly graded to indicate reliability. The reliability of the polarity interpretations is indicated in Figure 3 by the width of the respective polarity patterns (black for normal, stippled for reversed) in the polarity column. For example, within the lower part of Unit IV, a few samples displayed fairly standard demagnetization behavior overall, but displayed dramatic swings of direction at one or two temperature steps. In the temperature range of $400^{\circ}-500^{\circ} \mathrm{C}$, these samples' directions and

A)
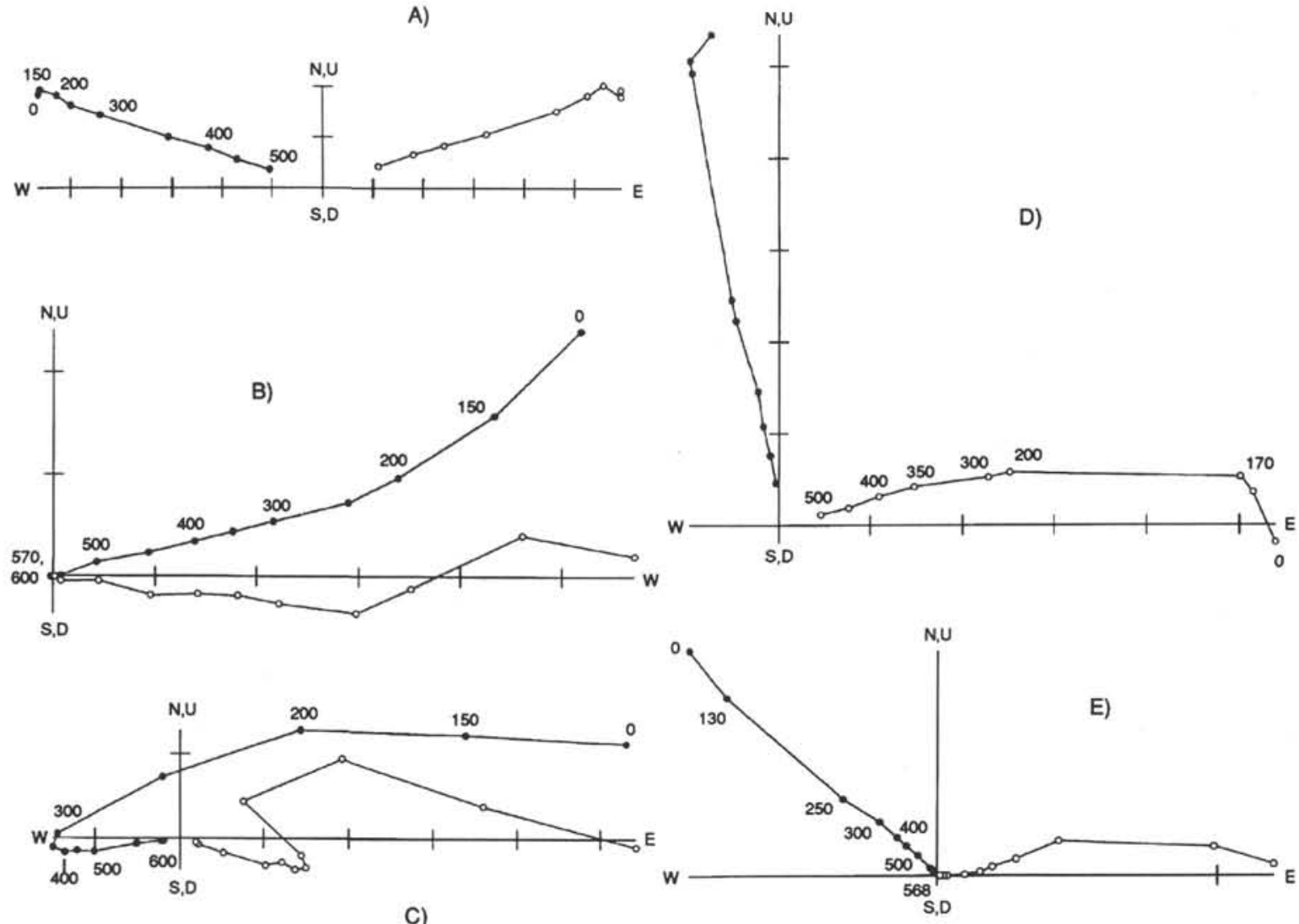

C)

Figure 2. A-E. Demagnetization responses of representative samples from Site 800 . These orthogonal projections plot inclination in the plane of the declination. The horizontal (vertical) components of the magnetization are shown as solid (open) circles; the distance from the origin is a measure of the total intensity of magnetization. Declination and inclination can be read directly from the respective projections. Scale divisions in $\mathrm{A}$ and $\mathrm{E}=5 \times 10^{-5} \mathrm{~A} / \mathrm{m} ; \mathrm{B}-\mathrm{D}=5 \times 10^{-6} \mathrm{~A} / \mathrm{m}$. Numbers indicate demagnetization temperature in ${ }^{\circ} \mathrm{C}$. 

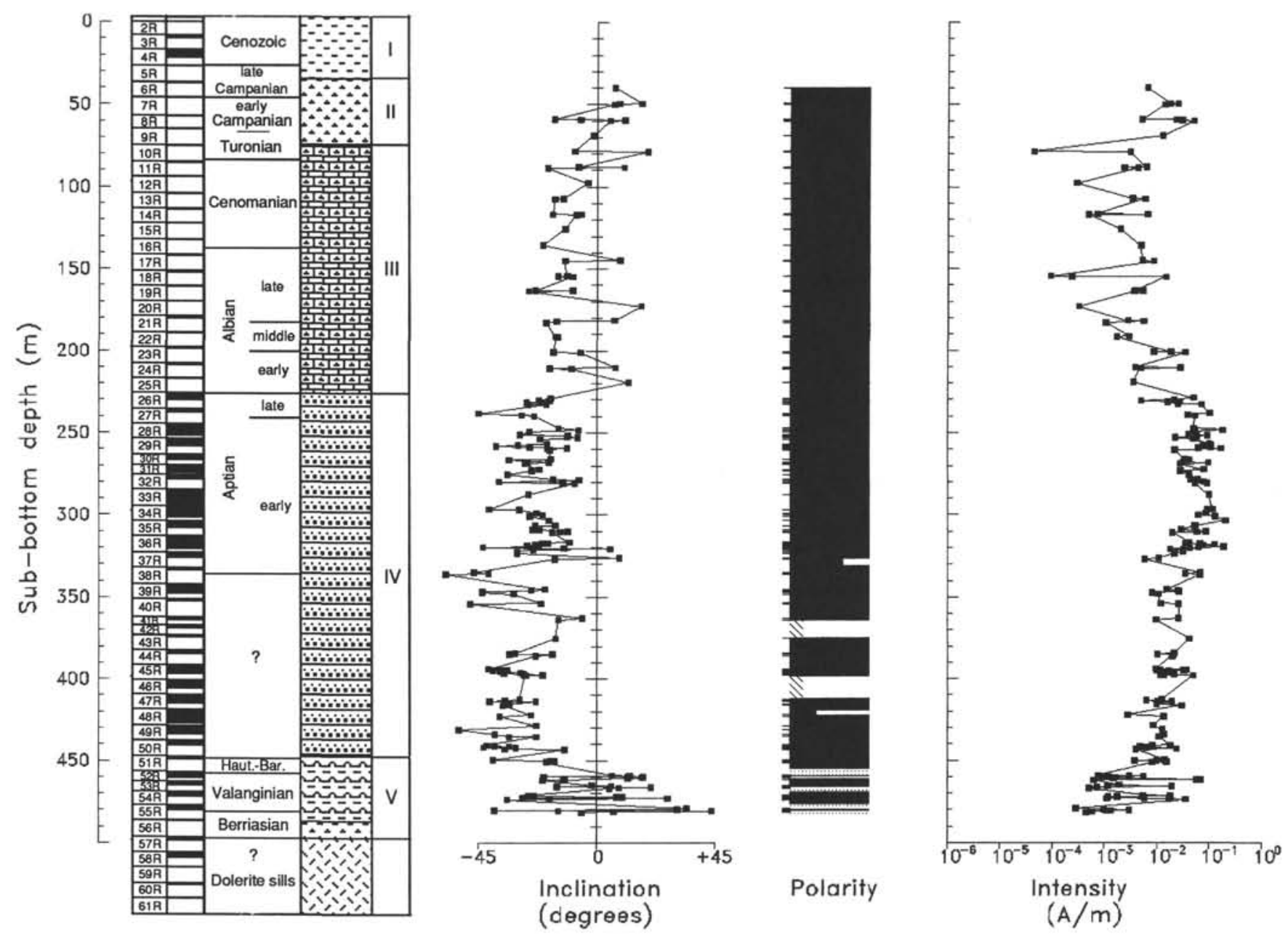

Figure 3. Stratigraphic plot of characteristic inclinations and intensities for the samples from Site 800 (indeterminate samples not plotted). Core number, recovery, age, lithology, and lithologic unit are shown on the left (from Shipboard Scientific Party, 1990a). Normal (reversed) polarity is shown as black (stippled); diagonal lines indicate unsampled regions of greater than $10 \mathrm{~m}$. The variation of width within the polarity column indicates certainty of polarity interpretation (see text). Sample positions are indicated by tick marks on the left side of the polarity column.

demagnetization behavior indicate normal polarity; however, because of the aberrant results at one or two temperature steps, the polarity column is filled to only two-thirds of its width to indicate the minor uncertainty. Another example of grading the polarity reliability is found in samples that showed erratic directional changes and poor linearity during demagnetization at the higher temperatures. Nevertheless, remanence directions at all demagnetization steps were similar, but with large errors to the line fit to them. These results are still consistent with Southern Hemisphere normal polarity, and such samples are considered suggestive of Cretaceous normal polarity, but their information is fairly uncertain and shown by only a one-third fill of the polarity column. The directional reliability of such samples is considered poor and is not used for paleolatitude. Substantial unsampled regions in the section (greater than $10 \mathrm{~m}$ ) are indicated by a hachured pattern in the polarity column. Both such intervals in this sequence are within the redeposited volcaniclastic turbidites, one representing poor recovery and the second, coarse sandstone.

Below about $100 \mathrm{~m}$ below seafloor (mbsf) and above about 450 mbsf, seven horizons yielded samples with positive inclinations that at first might suggest reversed polarity (Fig. 3). However, no directional change nor intensity increases upon demagnetization were observed, characteristics that are generally displayed by samples of reversed polarity. Because of the age of this interval (Albian-Aptian), and the overwhelming normal polarity of surrounding samples, these samples are most reasonably interpreted as from inverted pieces of core. It could be argued that these positive inclinations represent the higher dispersion expected from sites in near-equatorial latitudes; however, the inversion of the sign of the inclinations would place these sample inclinations in good agreement with the surrounding sample inclinations in most cases (Fig. 3), reinforcing the interpretation that these are probably inverted sections of core.

The lower part of the stratigraphic sequence at Site 800 is enlarged in Figure 4. Four of the five cores comprising lithologic Unit V (450 to $482 \mathrm{mbsf}$ in the figure) exhibit a large number of reversals. The polarity sequence observed here from discrete samples is quite similar to that observed aboard ship from whole-core measurements. This similarity is noteworthy because shipboard data were both: (1) nondeconvolved whole-core magnetization measurements, and more interestingly, (2) the result of only weak ( $20 \mathrm{mT}) \mathrm{AF}$ demagnetization of red sediments. The agreement between the two results suggests that the remanence in these red radiolarites and claystones is carried almost exclusively by the magnetite mineral series, and not, despite the pronounced red coloration, by the hematite mineral series. Moreover, shipboard low-field $\mathrm{AF}$ treatment was adequate to delineate the reversal sequence in red sediments.

Only two (or fewer) sections (out of six) were recovered for each of these five cores, indicating that a significant amount of time from this interval is not represented. Therefore, despite the large number 


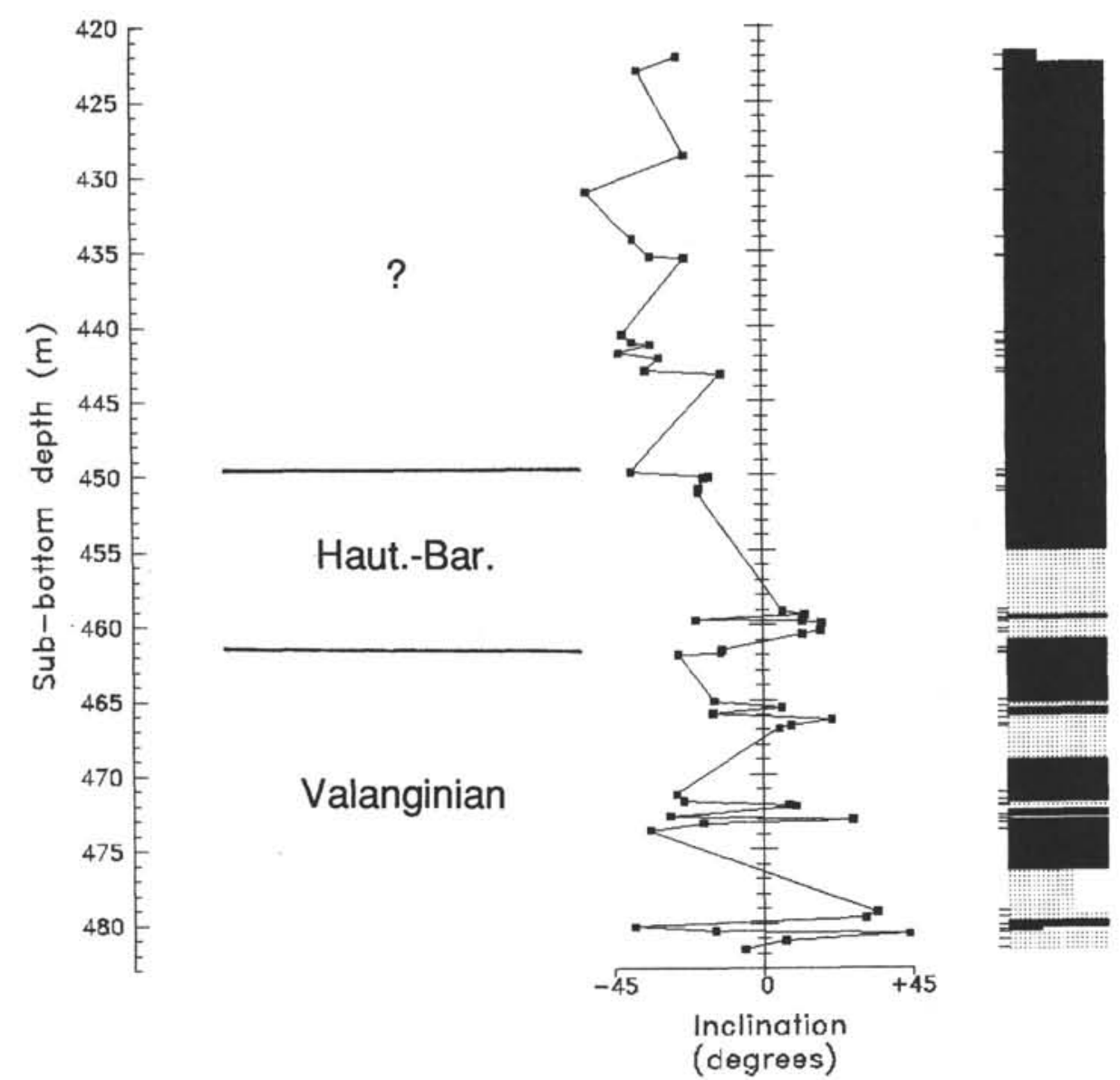

Figure 4. Enlargement of the polarity interpretation and characteristic inclinations of the Lower Cretaceous portion of Site 800, lithologic Unit V, at the base of the stratigraphic section.

of indicated reversals, many more are probably missing, and the sequence cannot be matched to specific anomalies of the marine magnetic anomaly pattern. Nevertheless, the Valanginian portion of the sequence bears significant resemblance to the Valanginian portion of the marine sequence; that is, to anomalies M10 to M14 (Haq et al., 1988; Ogg et al., 1988), in that both sequences show a large portion of reversed polarity, as well as a similarity in the relative lengths of normal and reversed polarity intervals. These results are in notable contrast to the largely normal polarity of the Valanginian portion of Sites 603 and 534 in the western Atlantic (Ogg, 1987). The multiple polarity of the Site 800 Valanginian sequence therefore rules out the suggestion (Ogg, 1987) of errors in the magnetic anomaly block model as a cause of the discrepancy between the western Atlantic cores and the anomaly model. The dominance of reversed polarity also reinforces the tentative Valanginian radiolarian biostratigraphic age assigned to this portion of this hole.

Paleolatitude was calculated from the sample suite after the data were assessed for probable reliability of characteristic inclination values. Amajority of the samples $(62 \%)$ from Site 800 exhibited linear trends to the origin in the higher stages of thermal demagnetization. The reliability of the directions of the other samples was assessed for the probability of complete removal of secondary vectors, and the sample directions categorized accordingly. One-third (32\%) of the total sample population, mostly located in the volcaniclastic turbidites trend very close (within $5^{\circ}$ or less), but not exactly to, the origin. These characteristic magnetization directions must be considered slightly less reliable than those of the univectorial-to-origin samples, but seem to give comparable values of inclinations. Two further classes of samples were observed, whose inclinations are either of poor reliability or are not meaningful. Eight samples (4\%) did not trend to within $5^{\circ}$ of the origin or had erratic demagnetization behavior (and thus had large errors associated with the line fits). Finally, four other samples $(2 \%)$ were indeterminate in direction and polarity, showing either the present field direction, a vertical (presumably drilling-induced) remanence, or purely erratic demagnetization behavior.

Instantaneous paleolatitude was calculated for each sample of the reliable and somewhat less reliable groups (the groups comprising $62 \%$ and $32 \%$ of the population). The results are shown in Figure 5; both groups are plotted together on the left side of the figure, while the right side displays only the most reliable samples. A clear trend in paleolatitude change is observed. The same trend is shown, both by the most reliable (univectorial-to-origin) samples and the slightly less magnetically clean samples, indicating that the remaining secondary magnetization in the second group does not significantly affect their characteristic magnetic directions and that these are also reliable.

The following paleolatitudinal history can be drawn from the data. Beginning in the Hauterivian-Valanginian, the site was located at about $7^{\circ}$ south latitude. An abrupt change in paleolatitude occurred at the boundary between the reddish radiolarian claystones and the base of the volcaniclastic turbidites, clearly indicating a hiatus in the sedimentary record. Above the hiatus paleolatitude values are about $18^{\circ} \mathrm{S}$. Within the interval of unknown age immediately above the hiatus (Fig. 5) two interpretations are possible. The majority of the samples (Fig. 5, left) suggest a continuous slow decrease of paleolatitudes, a decrease which extended through the Aptian to reach a value of about $7^{\circ} \mathrm{S}$ in the Albian. Alternatively, if only the most reliable data 

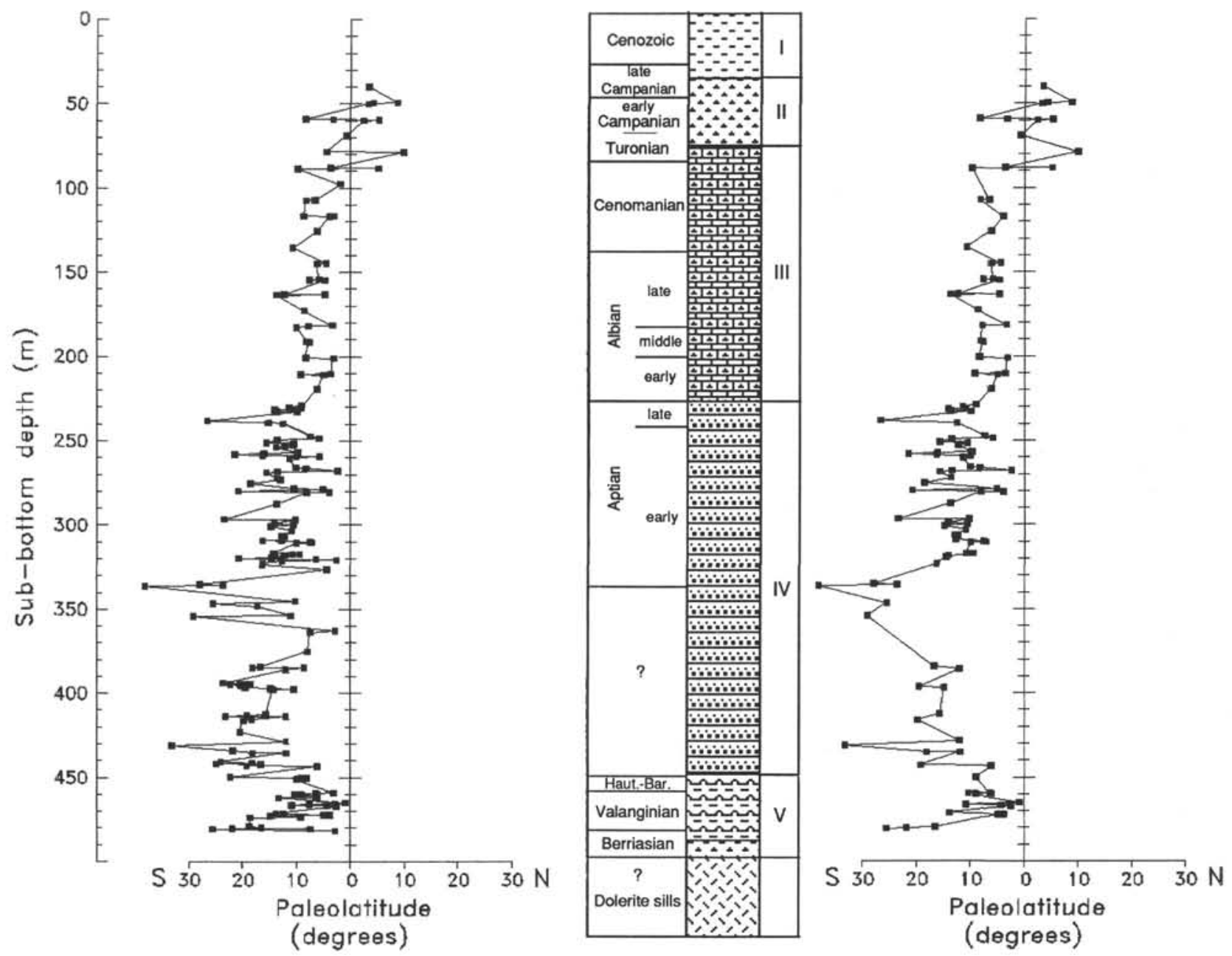

Figure 5. Site 800 stratigraphic plot of instantaneous paleolatitudes, shown with ages and lithologies from Shipboard Scientific Party (1990a). Left: paleolatitudes from each sample in the most reliable and slightly less reliable categories (see text); right: most reliable samples only.

are considered (Fig. 5, right), paleolatitude may have been approximately $15^{\circ} \mathrm{S}$ above the hiatus, and rose to about $27^{\circ} \mathrm{S}$ in the top of the unknown age interval, and decreased to lesser values $\left(\sim 12^{\circ} \mathrm{S}\right)$ in the Aptian. The second interpretation is more speculative because so few samples are reliable in the upper half of the unknown age interval, and the $27^{\circ} \mathrm{S}$ value is based on only a few samples that are vastly different from their neighbors. The $7^{\circ} \mathrm{S}$ paleolatitude of the Albian remained through most of the Cenomanian. This site reached the equator in late Cenomanian to Turonian-early Campanian time, and appears to possibly have resided a few degrees north of the equator by the late Campanian. After that, but still in the late Campanian, Site 800 moved into a paleogeographic region of very low sedimentation rates, such that only $40 \mathrm{~m}$ of sediment was deposited above the Campanian brown chert and porcellanite unit during the remainder of the site's history.

One of the prominent magnetization vectors removed from the samples during the course of demagnetization was a shallow, nearhorizontal vector of normal polarity. As shown in Figure 5, during the latter part of the Cretaceous Normal Polarity Superchron the site was situated in paleolatitudes within $5^{\circ}$ north or south of the equator. Therefore, the near-horizontal overprint may be a secondary magnetization acquired during that time period, or the ensuing time of very slow sedimentation rates in the early Tertiary. The near-horizontal magnetization vector removed from the Lower Cretaceous sediments (Unit V) may have been imprinted at the same time as that of the overlying sedimentary units or may have been imposed during the hiatus between the volcaniclastic unit and the Hauterivian-Barremian interval, again a time when the site was situated in low latitudes.

\section{SITE 801}

Two holes were drilled at this site to recover the complete sedimentary sequence; coring in the second hole (801B) began at the stratigraphic horizon at which Hole 801A was terminated. Paleomagnetic sampling began in lithologic Unit II, Campanian age brown chert recovered near the top of Hole 801A, and was continuous to the base of the sedimentary sequence (near the bottom of Hole 801B). Samples were taken from every section of every core in which recovery was sufficient to obtain a 1 -in.-diameter by at least 0.5 -in.long minicore. Cores 801A-8R, 801A-11R, 801B-9R, 801B-22R, and $801 \mathrm{~B}-32 \mathrm{R}$ did not have sufficient recovery to be sampled. Otherwise, samples were taken at an interval of one to as many as five minicores per $1.5 \mathrm{~m}$ section, depending on the amount of material available and competing sampling demands of other scientific investigations. Sampling was particularly dense in the Callovian-Bathonian lithologic unit in contact with the basalts of the Jurassic oceanic crust. Despite a relatively close-spaced sampling program in the recovered material, recovery was sufficiently poor that only 112 samples were obtained from the $393 \mathrm{~m}$ of Cretaceous and Jurassic sediments at this site. 
NRM directions had inclinations ranging from near-zero to both positive and negative $30^{\circ}$. The site is located at $18.6^{\circ} \mathrm{N}$ latitude $\left(156.4^{\circ} \mathrm{E}\right)$, and the axial dipole and presently observed inclinations are respectively $33.0^{\circ}$ and $21.0^{\circ}$. Very few of the NRM inclinations corresponded to values that would be produced by relatively recent secondary magnetizations; that is, few have inclinations of between $+20^{\circ}$ and $+40^{\circ}$. Remanent intensities (NRM) differ for the four lithologic units sampled. The brown chert/porcellanite (Unit II) averaged about $1 \times 10^{-1} \mathrm{~A} / \mathrm{m}$; the volcaniclastic turbidites (Unit III), approximately $7 \times 10^{-1} \mathrm{~A} / \mathrm{m}$; the brown radiolarite (Unit IV), $1 \times 10^{-1}$ $\mathrm{A} / \mathrm{m}$; and the red radiolarite and claystone of Unit $\mathrm{V}, 3 \times 10^{-2} \mathrm{~A} / \mathrm{m}$.

One sample each of a series of sample pairs from the same stratigraphic horizons were demagnetized by $\mathrm{AF}$ and thermal methods for comparison. In all cases, the samples demagnetized with alternating fields did not decay univectorially toward the origin of orthogonal axes plots. In contrast, all of the samples treated by thermal demagnetization did display univectorial decay to the origin, observed particularly in the temperature range between $300^{\circ}$ or $400^{\circ} \mathrm{C}$ and $570^{\circ} \mathrm{C}$. Also notable in the response to $\mathrm{AF}$ demagnetization was that the small anhysteretic remanence commonly induced by our equipment above $60 \mathrm{mT}$ was more prominent in these samples: it formed a significant part of the resultant remanent magnetization, and did so at much lower demagnetization levels than for samples from either of the other two sites, even though all samples from all three sites were treated at the same time.

The difference in response of the Site 801 samples to thermal vs. AF demagnetization, as well as the observation that Site 800 samples were better treated by thermal demagnetization, suggests that this demagnetization technique is best for the sediments of this area. All Site 801 samples were thermally demagnetized, using similar or the same temperature steps used for Site 800 . The demagnetization response of Site 801 samples differs with lithology, so the sedimentary units will be described separately. As illustrated in the following discussions, in general, thermal demagnetization clearly separated the magnetization vectors for nearly all samples from each lithologic unit of this hole.

The highest sedimentary interval sampled (Unit II) showed both normal and reversed polarity magnetizations. The Campanian samples of this brown chert-porcellanite unit (Core 801A-7R) were entirely reversed; the remainder of the unit has normal polarity. Most samples from this lithology decayed univectorially to the origin of orthogonal axes plots above about $500^{\circ} \mathrm{C}$. In some cases univectorial decay begins at somewhat lower temperatures, and occasionally only above $550^{\circ} \mathrm{C}$. Above $570^{\circ} \mathrm{C}$ all coherent remanence is lost. Samples with representative demagnetization behaviors are shown in Figures $6 \mathrm{~A}$ and $6 \mathrm{~B}$.

The volcaniclastic turbidites of Unit III are entirely of normal polarity, consistent with their Cenomanian to Albian and older ages that indicate their deposition during the Cretaceous Normal Polarity Superchron. Most of these samples display demagnetization trends that are univectorial to the origin. Figure $6 \mathrm{C}$ is typical of the samples in this interval. Secondary magnetizations often are completely removed by $350^{\circ} \mathrm{C}$, some by $250^{\circ} \mathrm{C}$ (or lower), but occasionally not until $450^{\circ} \mathrm{C}$. All remanence is lost above $570^{\circ} \mathrm{C}$. A near-horizontal magnetization, as was observed in the volcaniclastic turbidites and older sediments of Site 800 is observed in about one-half to two-thirds of the samples, as illustrated in Figure $6 \mathrm{D}$ between $200^{\circ} \mathrm{C}$ and $240^{\circ} \mathrm{C}$. This vector is usually removed between $150^{\circ} \mathrm{C}$ to $200^{\circ} \mathrm{C}$, or at $250^{\circ} \mathrm{C}$; in a few samples it is still present at $400^{\circ} \mathrm{C}$, but it is always removed by $450^{\circ} \mathrm{C}$,

The brown radiolarites of Unit IV displayed both normal and reversed polarities, with reversed polarity dominant. Most samples showed univectorial decay to the origin of orthogonal axes plots, observed after heating to temperatures between $500^{\circ} \mathrm{C}$ to $540^{\circ} \mathrm{C}$. A small fraction of the samples displayed univectorial decay to the origin above $250^{\circ} \mathrm{C}$ to $350^{\circ} \mathrm{C}$. Figures $6 \mathrm{E}$ and $6 \mathrm{~F}$ show typical normal and reversed samples. The vectors removed during demagnetization are the present/axial field direction and the horizontal magnetization observed in the overlying volcaniclastic unit.

The red radiolarites overlying Jurassic basement (Unit V) show both normal and reversed directions. Twelve samples were taken from the three cores representing this unit (801B-33R through 801B-35R); five samples are of normal, and seven of reversed, polarity. Figure 7 displays the demagnetization responses of samples from this unit. In both the normal and reversed samples the same two magnetization vectors are removed during demagnetization as were observed in the overlying lithologic units; in some samples only one of the two vectors is seen, while in others both were observed. In this unit, the horizontal magnetic vector is clearly of normal polarity as it has declinations similar to those of the normal polarity samples and antipodal to those of samples of reversed direction; inclinations of this vector are of nearly zero to slightly negative values.

The reversed polarity samples of Unit $V$ are atypical with respect to other reversed samples from this site and from the other sites: five of the seven samples interpreted to be of reversed polarity do not show the directional influence of contamination by a secondary normal polarity (e.g., present day) magnetization. That is, these samples exhibit very little of the directional change during demagnetization that is typically associated with reversed samples higher in this hole and at other sites (typical reversed sample behavior was illustrated in Figs. 6A and 6F). Despite the lack of directional change, the samples display large increases in intensity during demagnetization, the other characteristic of a reversed sample overprinted by a normal polarity secondary magnetization. Usually this is observed through the $350^{\circ} \mathrm{C}$ heating step in these samples. An apparent continuum of demagnetization response is observed in Unit V samples, from a response displaying both large directional change and an increase in intensity, to samples showing no directional change, but large increases of intensity. Figures 7B through 7E illustrate this range of response observed in the samples of Unit V. The sample illustrated in Figure 7B is typical of reversed polarity samples elsewhere; it is the only one of the reversed samples of Unit V to display this much directional change during demagnetization. Figure $7 \mathrm{C}$ shows the sample exhibiting the second-greatest amount of directional change, while Figures 7D and 7E are typical of most of the reversed samples of this unit. The figures illustrate the continuum of demagnetization behavior; were it not for these intensity increases, it would be quite difficult to recognize that samples such as those in Figures 7D and 7E are of reversed polarity. This point in stressed because of the consequences of the polarity interpretation for the inference of hemisphere of residence during the mid-Jurassic; the hemisphere uncertainty is exacerbated by the low inclinations that prevailed at this site during this time. If the polarity interpretation is not correct, the site may have resided in the Northern, rather than Southern, Hemisphere in the Callovian.

The directions for each sample from Site 801 were determined by the least-squares technique, as discussed for Site 800 , and the same two grading schemes, one for directional and one for polarity reliability, were applied. The characteristic inclinations determined by least squares analysis are shown in stratigraphic succession in Figure 8. The reversed polarity in the Campanian age sediments (Shipboard Scientific Party, 1990b) at the top of the hole indicates that these sediments are actually of early Campanian age, corresponding to the time interval of marine magnetic anomaly $33 \mathrm{R}$. Thereafter, normal polarity is observed through the rest of Unit II and throughout Unit III, consistent with the Coniacian through Albian biostratigraphic ages and reflecting the Cretaceous Normal Polarity Superchron. Many of the samples within the Valanginian through Tithonian sediments of Unit IV and those in the Callovian-latest Bathonian of Unit $\mathrm{V}$ are of reversed polarity. This preponderance of reversed directions is consistent with the dominance of reversed polarity during those time periods (Larson and Hilde, 1975; Steiner and Ogg, 1988). Samples at an additional seven horizons, within Units II and III, have positive inclinations (Fig. 8) and therefore might be thought to be of 

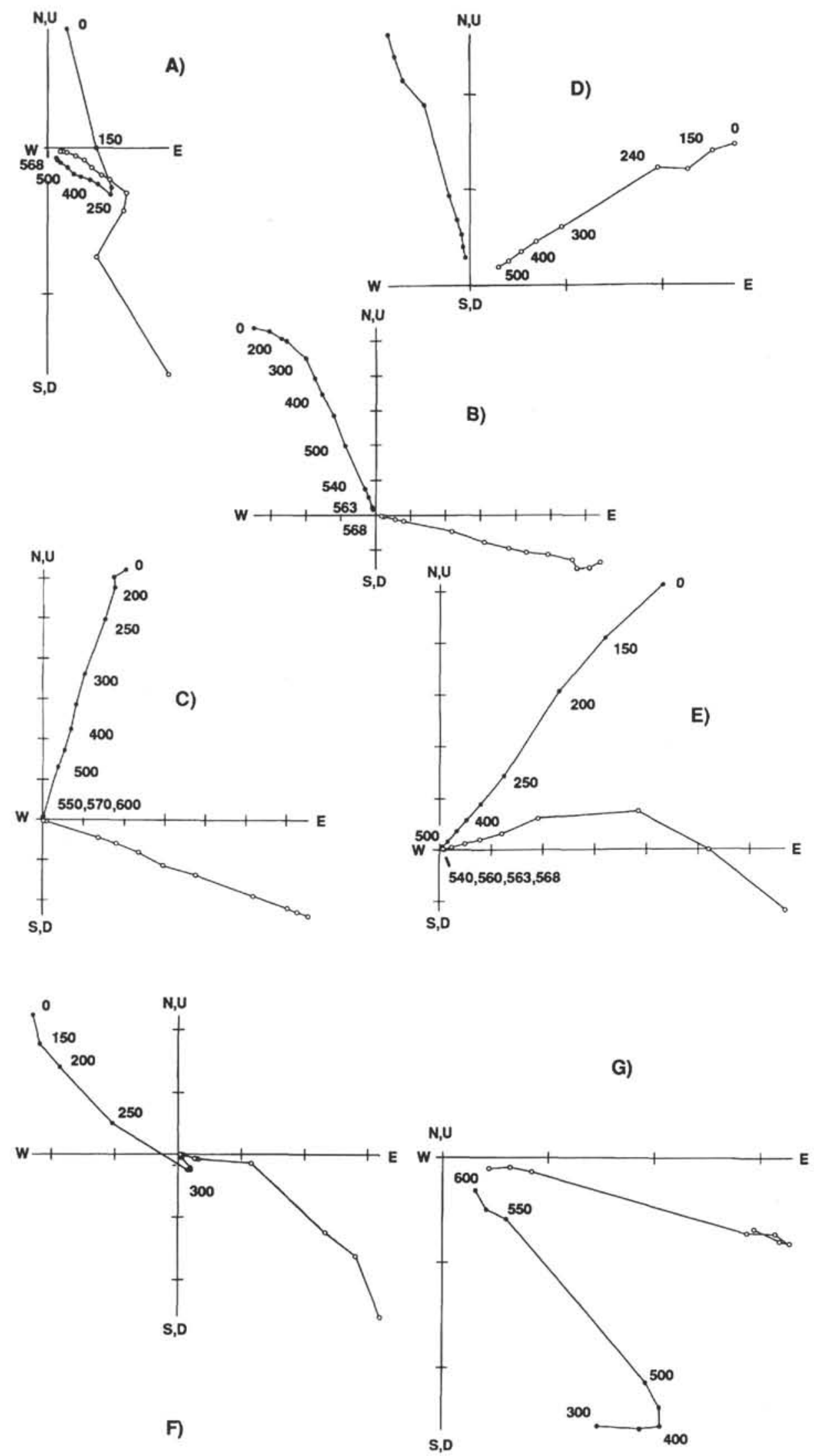

Figure 6. A-G. Demagnetization responses of representative samples from lithologic Units II through IV of Site 801. The horizontal (vertical) components of the magnetization are shown as solid (open) circles (see Fig. 2). Scale divisions: $A$ and $B=5 \times 10^{-6} \mathrm{~A} / \mathrm{m} ; \mathrm{C}$ and $\mathrm{D}=5 \times 10^{-5} \mathrm{~A} / \mathrm{m} ; \mathrm{E}=1 \times 10^{-5} \mathrm{~A} / \mathrm{m} ; \mathrm{F}=1 \times 10^{-6} \mathrm{~A} / \mathrm{m}$, and $\mathrm{G}($ enlargement of $\mathrm{F})=5 \times 10^{-7} \mathrm{~A} / \mathrm{m}$. 


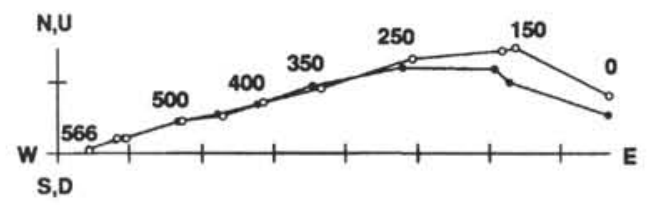

A)

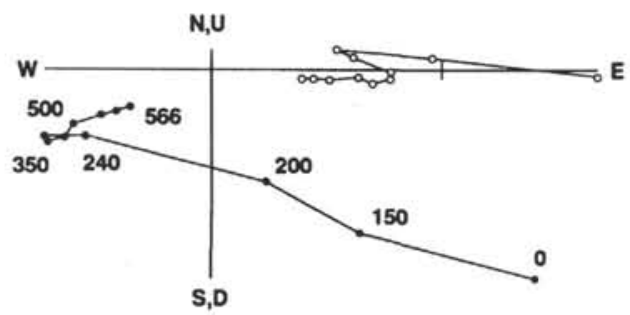

B)

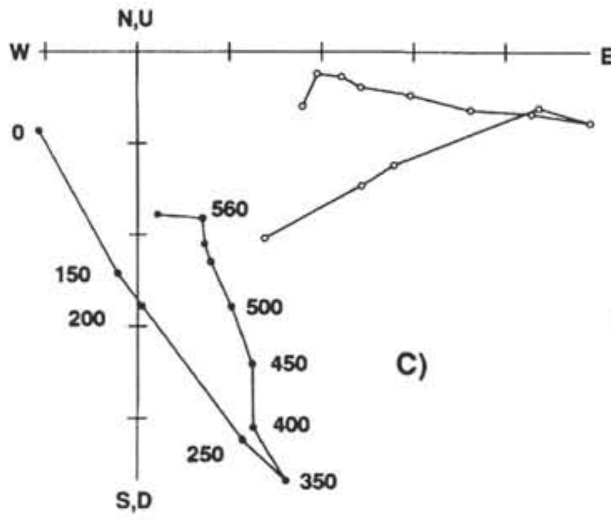

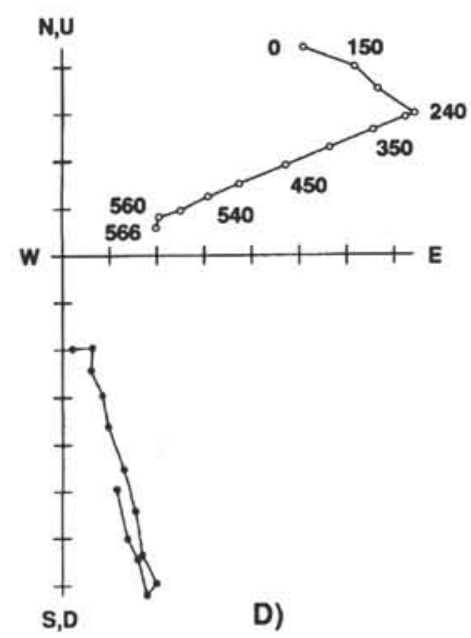

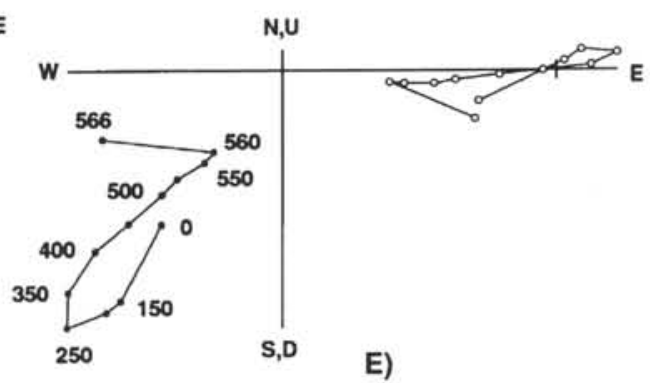

E)

Figure 7. A-E. Demagnetization responses of samples from the Callovian-Bathonian red radiolarites (lithologic Unit V) of Site 801. The horizontal (vertical) components of the magnetization are shown as solid (open) circles (see Fig. 2). Scale divisions: $\mathrm{A}-\mathrm{E}=5 \times 10^{-7} \mathrm{~A} / \mathrm{m}$.

reversed polarity. However, those samples exhibited neither directional change nor intensity increases characteristic of reversed magnetization during demagnetization, and therefore are best explained as samples from inverted pieces of core.

Instantaneous paleolatitude was calculated for each sample in the two categories of most reliable (81\%) and slightly less reliable (9\%) samples (see "Site 800" discussion). In the entire Site 801 sample population, only eight were not reliable (see "Site 800 " discussion) for paleoinclination/paleolatitude and only one sample was indeterminate in direction and polarity; therefore, a total of only $9 \%$ of the samples of this site could not be used for paleolatitude. The paleolatitudes calculated for each sample are shown in stratigraphic succession in Figure 9.

The data indicate that Site 801 was in the Southern Hemisphere during the entire time spanned by this stratigraphic record, from the Campanian to the Callovian/Bathonian boundary. Low southerly latitudes are indicated for this site during the Callovian-Bathonian $\left(\sim 6^{\circ} \mathrm{S}\right)$, followed by a move to an equatorial position during the Kimmeridgian and Tithonian. From the late Tithonian through Valanginian, the computed paleolatitude is near $4^{\circ} \mathrm{S}$. A moderately smooth record from the overlying volcaniclastic turbidite strata (lithologic Unit III), shows that the site has moved farther south (during "?" time) and continues moving southward, to a maximum value of about $13^{\circ} \mathrm{S}$ in the middle
Albian. Above or within the middle Albian portion of this record, inclinations slowly shallow, indicating the plate ceased the southward motion and began to move northward; most of this southward and northward motion occurred within the "?" (presumably Aptian) time and the Albian. By between Cenomanian and Coniacian times, the sparse data imply that the site had returned to a latitude of about $4^{\circ} \mathrm{S}$; that latitude is also indicated by the few data for Campanian time. Hence, the equatorial crossing of this site is not clearly indicated by the paleolatitudes, but taking account of the dispersion in the Cenomanian through Campanian data and the trend in the paleolatitudes between the middle Albian and the Coniacian, the equatorial crossing is inferred to have been between Santonian and Campanian time.

It should be recognized that the interpretation of southerly paleolatitudes during Callovian-Bathonian times is entirely dependent on having correctly interpreted the polarity of samples that seem to have only minor secondary magnetizations overprinted on reversed polarity Jurassic magnetization. If this interpretation of reversed polarity were incorrect, then the site would have to be interpreted as being in the Northern Hemisphere during the Callovian-Bathonian and the formation of the Jurassic Quiet Zone. Not only is the reversed interpretation thought more likely to be correct because of the significant increases in intensity during demagnetization, but also because this interpretation results in all samples of each polarity possessing 

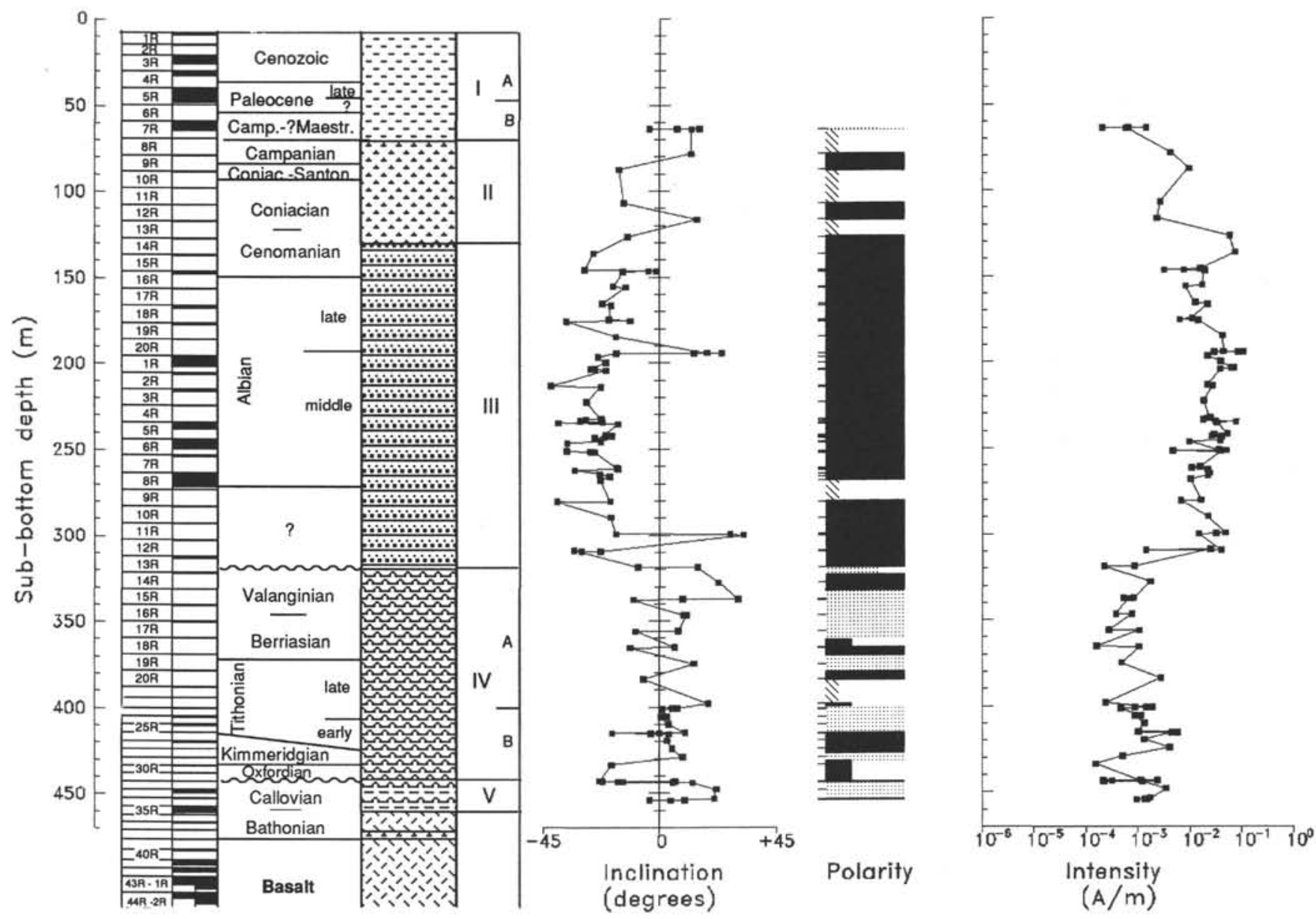

Figure 8. Stratigraphic plot of characteristic inclinations and intensities for the sedimentary samples from Site 801. Core number, recovery, age, lithology, and lithologic unit are shown from left to right (from Shipboard Scientific Party, 1990b). The polarity interpretation column displays normal (reversed) polarity as black (stippled); diagonal lines indicate unsampled regions of greater than $10 \mathrm{~m}$. The variation in width within the polarity column indicates certainty in the polarity interpretation (see text, Site 800). Sample positions are indicated on the left side of the polarity column.

like signs of inclination, whereas the normal polarity interpretation causes a mixture of signs (and wide dispersion of inclination values, $\pm 20^{\circ}$ ) for each polarity group.

After the site crossed the equator (between Santonian and Campanian, or possibly after Campanian time), it entered a regime of very low rates of sedimentation. The origin of the commonly observed secondary magnetization with nearly horizontal inclination (and normal polarity) may have been acquired during the time the site was near the equator. The fact that long periods of normal polarity are not common in the Tertiary, as compared to the Cretaceous, may suggest that this secondary magnetization may have been acquired in the Santonian to Maestrichtian.

\section{SITE 802}

Younger sediments were sampled at this site than at the other two sites because a substantial Early Tertiary sequence was recovered. Miocene to Paleocene sediments were sampled, although large portions of the Miocene sequence were composed of sediments too coarse to yield reliable paleomagnetic directions. Therefore, sampling was restricted to the portions that had grain sizes that could be expected to be favorable, or at least marginally so, to the retention of possible detrital remanent magnetism. Sampling began in the lower part of the early Miocene sediments and was continuous, within the constraints of the occurrences of suitable lithologies, through the Paleocene. Below the Tertiary, lithologies are similar to those at the other sites, and the entire Cretaceous sequence was abundantly sampled, yielding a section of late Campanian through ?late Aptian age, the lowest sediments of which lie on Cretaceous extrusive basalt. Samples generally were taken at intervals of one to two samples per recovered section $(1.5 \mathrm{~m})$ of core. A total of 162 sedimentary samples were measured for this site.

NRM inclinations ranged between $-30^{\circ}$ and $+30^{\circ}$, but negative values generally were more common. The presently observed and axial dipole inclinations for this site $\left(12.1^{\circ} \mathrm{N}, 152.3^{\circ} \mathrm{E}\right)$ are respectively $8.3^{\circ}$ and $23.2^{\circ}$. NRM intensities were generally between $1 \times$ $10^{-1}$ and $5 \times 10^{-1} \mathrm{~A} / \mathrm{m}$, except for those of lithologic Unit III, in which intensities were significantly lower, averaging about $8 \times 10^{-2} \mathrm{~A} / \mathrm{m}$. This lower remanent intensity is consistent with the lithologic composition, as nannofossil chalks are usually more weakly magnetized than many other rock types.

Six samples from the same stratigraphic levels were comparatively demagnetized by both $\mathrm{AF}$ and thermal means. The two methods produced the same demagnetized directions in all cases. However, AF demagnetization caused a linear decay that always slightly missed the origin of orthogonal axes plots. Thermal demagnetization always induced decay straight to the origin. Nevertheless, the directions of the least-squares lines fit to the AF trends were essentially the same as those produced by thermal demagnetization. This result suggests that only a small amount of secondary magnetization, not sufficient to significantly alter the characteristic direction, is present and is held in minerals with a blocking temperature spectrum below that of the 

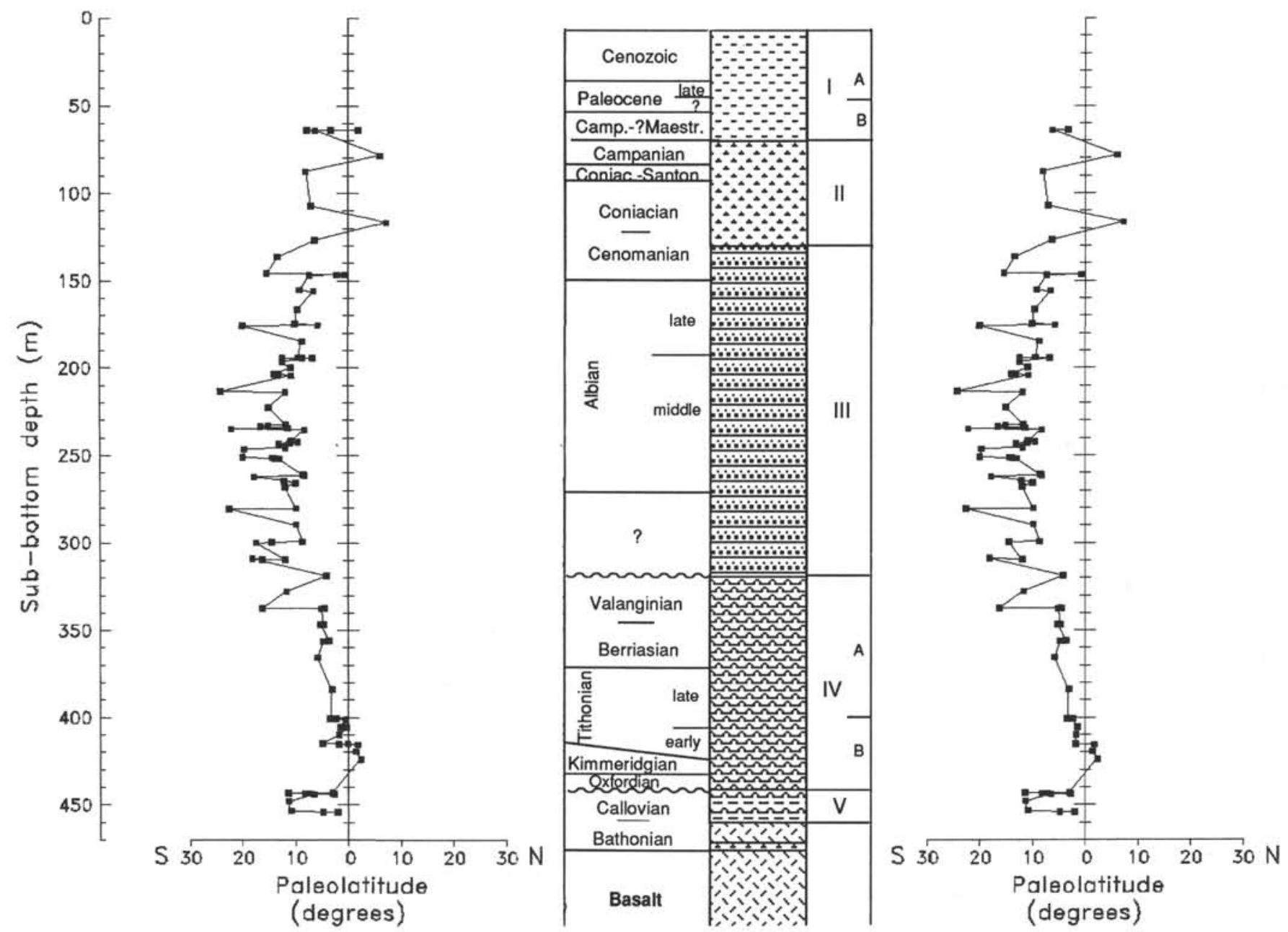

Figure 9. Site 801. Stratigraphic plot of paleolatitude calculated for each sample of the most reliable and slightly less reliable categories (see text, Site 800). Left: paleolatitudes from both the most reliable and slightly less reliable samples; right: most reliable samples only. Ages and lithologies from Scientific Party (1990b). Note that abrupt changes in paleolatitude correspond to indicated unconformities.

characteristic remanence, but having a coercivity which is the same or greater than that of the characteristic magnetization. It is likely that this magnetic carrier is an oxidized product of some of the grains of the carrier of characteristic magnetization. Directions of magnetization are unstable above $550^{\circ} \mathrm{C}$; therefore, it is concluded that the characteristic remanence carrier is probably a mineral in the titanomagnetite series.

As a result of the comparison of $\mathrm{AF}$ and thermal demagnetization, all samples were thermally demagnetized using the temperature steps employed for the previous sites. The response to thermal demagnetization differed for the different lithologies, and will be discussed for each. For the top lithologic unit studied, Unit II, only two samples were taken, both close to the base of this tuff and calcareous claystone unit. Both samples responded fairly well to demagnetization, exhibiting linear trends to the origin. However, the two samples have opposite signs of their characteristic inclinations (although one had smaller error and more steps defining the linear portion of the demagnetization trend). Similar disparities in inclination sign of seemingly same polarity samples are observed in underlying lithologic Unit III, and may reflect an equatorial site location and the associated greater dispersion of magnetic directions.

Samples from Unit III (nannofossil chalk) exhibited normal underlain by reversed polarity, with two shorter intervals of normal polarity within the reversed portion. The demagnetization behavior is illustrated in Figures $10 \mathrm{~A}$ and 10B. Samples in this unit display demagnetization trends linear to the origin between $350^{\circ} \mathrm{C}$ and $550^{\circ} \mathrm{C}$. Polarity is readily and unambiguously determined in the samples of Unit III, but within individual sample demagnetization responses, there are greater differences between directions from consecutive temperature steps than in other lithologic units. This characteristic is probably associated with the weaker remanent magnetization intensity and hence greater influence of instrument noise. Samples not displaying trends to the origin or that exhibit large errors associated with lines fit to the portion of the demagnetization path trending to the origin commonly lost all magnetization above $450^{\circ} \mathrm{C}$ and displayed highly erratic behavior between $500^{\circ} \mathrm{C}$ and $560^{\circ} \mathrm{C}$.

Unit IV, brown and mottled brown claystone of Paleocene and late Campanian age, is represented by only a small amount of preserved section, with an unconformity between the Paleocene and the Campanian portions (Shipboard Scientific Party, 1990c). The samples are mostly of normal polarity, and above $250^{\circ} \mathrm{C}$ are linear to the origin with very small errors associated with the line fits. A typical example is shown in Figure 10C. Three samples of reversed polarity occur near the top of Core $802 \mathrm{~A}-38 \mathrm{R}$, that is, near the top of the recovered upper Campanian; these samples are also, at temperatures above $250^{\circ} \mathrm{C}$, univectorial to the origin with quite small errors associated with the line fits. Pairs of samples were taken to test the difference in magnetic direction between the uniformly brown colored claystone and the mottled brown claystone. No difference in magnetization characteristics or direction was found. 


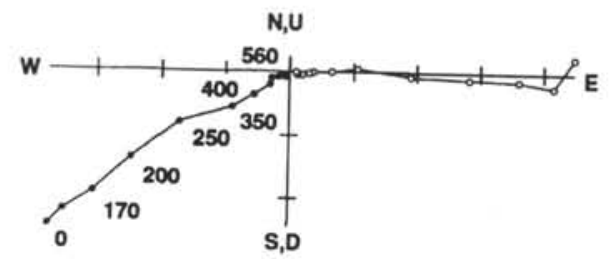

A)
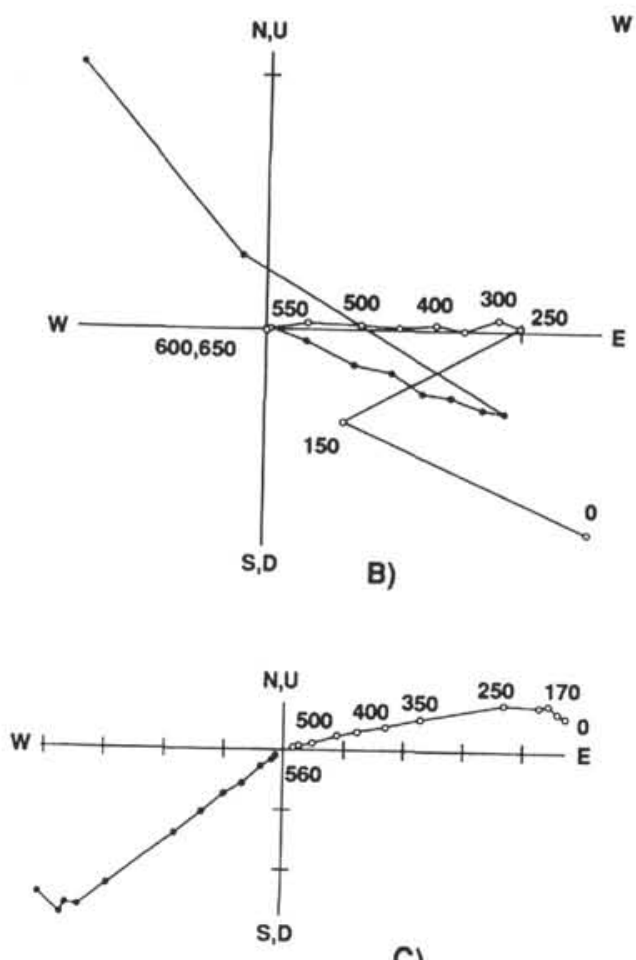

C)

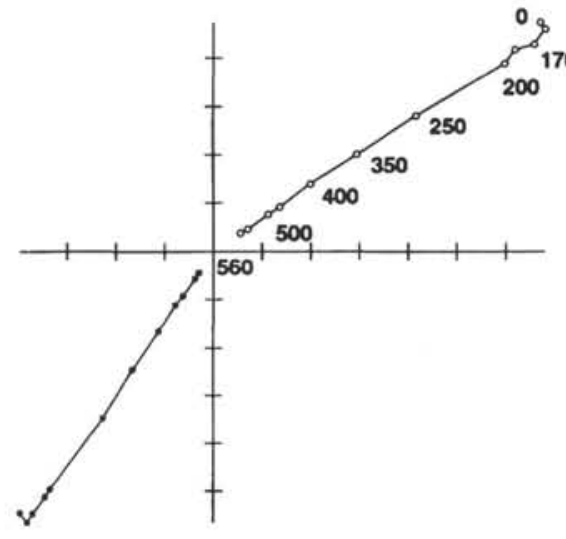

F)

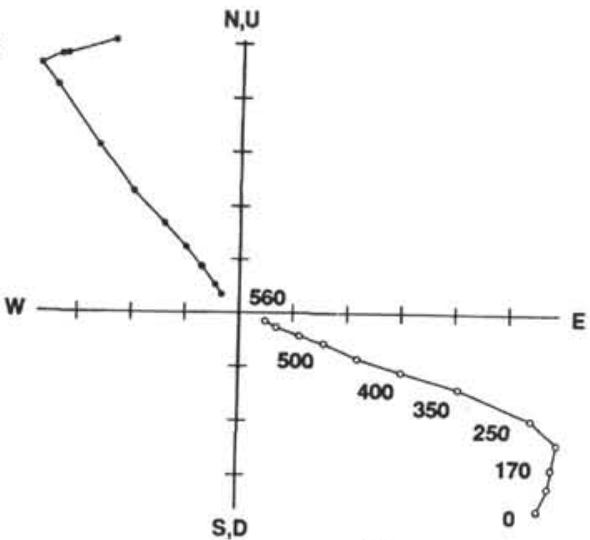

D)

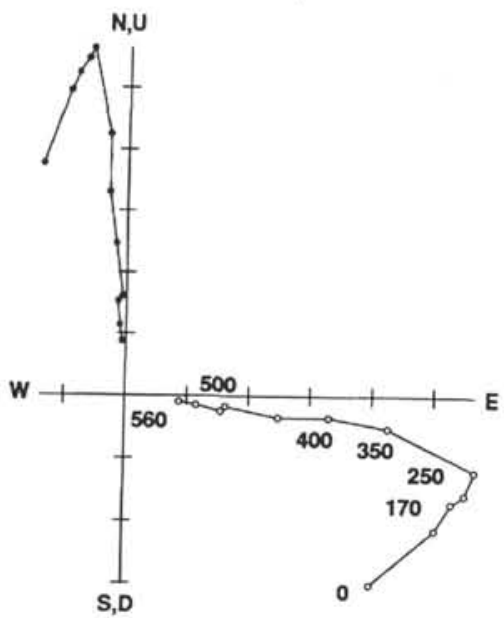

E)

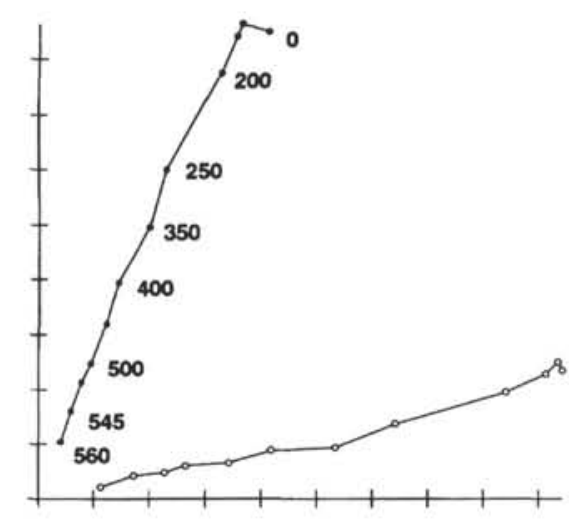

G)

Figure 10. A-G. Demagnetization responses of representative samples from Site 802. The horizontal (vertical) components of the magnetization are shown as solid (open) circles (see Fig. 2). Scale divisions on orthogonal axes plots: $\mathrm{A}=1 \times 10^{-6} \mathrm{~A} / \mathrm{m} ; \mathrm{B}=5 \times 10^{-6} \mathrm{~A} / \mathrm{m} ; \mathrm{C}=5 \times 10^{-5} \mathrm{~A} / \mathrm{m} ; \mathrm{D}$ and $\mathrm{E}=1 \times 10^{-5} \mathrm{~A} / \mathrm{m} ; \mathrm{F}=5 \times 10^{-5} \mathrm{~A} / \mathrm{m}$; $\mathrm{G}=1 \times 10^{-5} \mathrm{~A} / \mathrm{m}$. 
Volcaniclastic turbidites make up Unit V. In the upper half of this unit (Cores $802 \mathrm{~A}-40 \mathrm{R}$ through $802 \mathrm{~A}-44 \mathrm{R}$ ) there are peculiarities in the magnetic signature, which prompted a detailed examination of the magnetic behavior of this unit to determine whether it was associated with variations in lithology. Two aspects of the magnetization of those cores are peculiar: the inclinations of the samples are all positive (Fig. 11), and a significant number of these samples display increases of intensity upon demagnetization, suggesting the removal of a vector of opposite polarity. Sample behaviors illustrated in Figures 10D and 10E are typical. These characteristics seem to suggest reversed polarity without displaying much change in direction upon demagnetization, a characteristic usually associated with reversed polarity. Moreover, the age of these sediments is late Campanian to Santonian, times of definitely normal polarity.

Interpretation of these demagnetization results as indicating reversed polarity is only feasible if the age of the sedimentary sequence is early Campanian, reflecting the reversed polarity of anomaly $33 R$. Although some cores of this peculiar interval do contain a species of nannofossil known only from the early Campanian ( $B$. hayi), the majority of species represent the middle or late Campanian. Therefore, it does not seem possible for the age to be early Campanian or that this is a record of the anomaly $33 \mathrm{R}$ reversed polarity interval. Moreover, the lowest two cores of this interval are definitely Santonian in age and therefore should be of normal polarity.
An alternative explanation is that this interval contains a peculiar mineralogy that somehow causes these magnetic characteristics. This is suggested by a definite lithologic difference between these samples with positive inclinations and the samples above and below with negative inclinations. The positive inclinations correspond to an interval of gray-colored claystone and sandstone, whereas the rest of Unit V has green or gray-green coloration. In addition, throughout the interval of positive inclinations, vectors that have nearly vertical positive or negative inclinations are commonly removed. Such vertical subtracted magnetizations suggest a superposed drilling remanence. The steep secondary magnetizations are rarely seen outside of this interval, a fact that strongly suggests a lithologic influence on the magnetization. Moreover, the positive steep vectors are generally observed in samples whose characteristic remanence has positive inclination, while the steep negative ones are observed in samples of negative characteristic inclination. This implies an incomplete removal of the influence of the secondary magnetization on the magnetization that appears characteristic after the completion of demagnetization.

Characteristic inclinations change abruptly to negative values below Core $802 \mathrm{~A}-44 \mathrm{R}$ within Unit V (and below the entirely gray coloration), and remain negative for the remainder of the unit. These samples are primarily similar to other samples above and below Unit $\mathrm{V}$ and to the samples from the other sites of this leg. They generally have little secondary magnetization (Fig. 10F). No samples within the

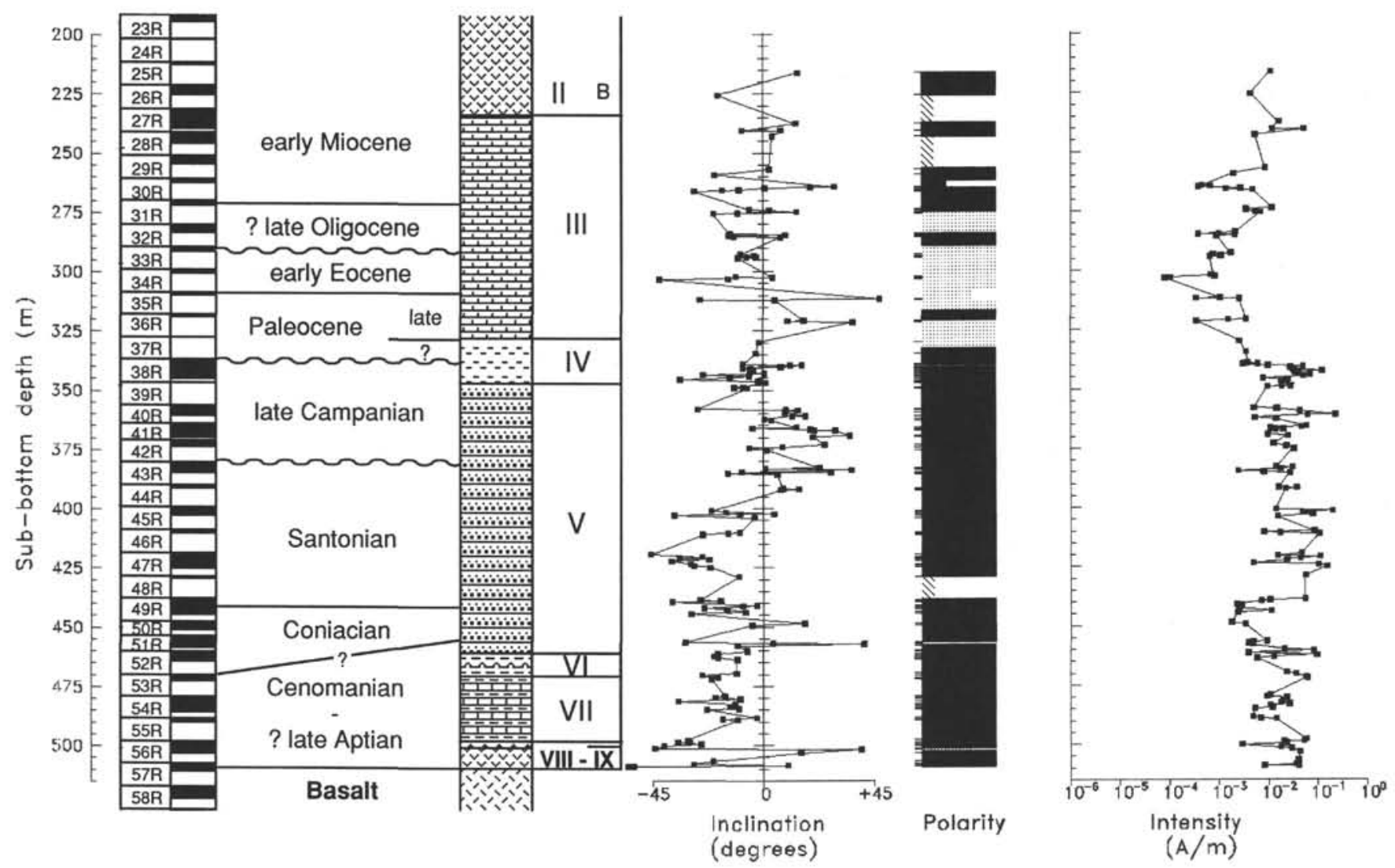

Figure 11. Characteristic inclinations and intensities for the sedimentary samples of Site 802. Core number, recovery, age, lithology, and lithologic unit are shown from left to right (from Shipboard Scientific Party, 1990c). The polarity interpretation column displays normal (reversed) polarity as black (stippled); diagonal lines indicate unsampled regions of greater than $10 \mathrm{~m}$. The variation in width of the polarity column designates certainty of polarity interpretation (see text, Site 800). Sample positions are indicated on the left side of the polarity column. 
lower half of Unit V display the abnormal behavior described for the upper half of the unit. Two samples at the base of the unit appear to be of reversed polarity; they are Coniacian in age. Samples from Core $802 \mathrm{~A}-47 \mathrm{R}$, in the lower part of Unit V, have steeper magnetizations than the rest of the unit, but exhibit very stable magnetic behavior (Fig. 10F). This core has a higher proportion of siltstone, whereas the other cores of Unit V are sandstone or claystone, but the significance of these associations is unclear.

Lithologic Units VI, VII, VIII, and IX exhibit magnetization behavior indicating that secondary magnetizations are of relatively small proportions. Nearly all samples display demagnetization trends that are univectorial to the origin of orthogonal axes plots, and commonly beginning at relatively low temperatures of $250^{\circ} \mathrm{C}$ or $350^{\circ} \mathrm{C}$. All samples are of normal polarity with one possible exception at $30 \mathrm{~cm}$ in Core $802 \mathrm{~A}-56-4$, although a reversed polarity interpretation of this sample is not entirely certain due to its somewhat ambiguous demagnetization behavior. In the samples of these lithologic units, a horizontal component is quite commonly removed at low temperatures, a magnetization similar to that observed in the other holes of this leg. This component is particularly prominent in the volcaniclastic turbidites of the other two sites, but is only infrequently observed in the volcaniclastic turbidites of this site.

The direction for each sample was determined by the least-squares technique discussed for the other sites, and was similarly graded for direction and polarity reliability. The stratigraphic sequence of magnetic inclinations and polarity from this hole is shown in Figure 11. The extensive reversed polarity in the late Oligocene, early Eocene, and late Paleocene age portions of the section recovered in this hole is in good agreement with the magnetic polarity time scale (e.g., Harland et al., 1989; Haq et al., 1988), as all three of these time intervals are dominantly of reversed polarity.

Within the Cretaceous section, three quite short stratigraphic intervals showed characteristics of reversed polarity. One is in the late Campanian part of the section, and consists of three samples. These are all of clearly reversed characteristic magnetization, exhibiting substantial directional change and increases in remanent intensity during demagnetization in addition to positive inclinations. The interval is in the top section of Core $802 \mathrm{~A}-38 \mathrm{R}$, and may correspond to marine magnetic anomaly $32 \mathrm{R}$, thereby suggesting that this core is actually early Maestrichtian rather than late Campanian in age.

Farther down-section, two samples in the Coniacian display magnetization characteristics suggesting reversed polarity (section 3 of Core 802A-51R), as does one sample in the ?upper Aptian (section 4 of Core 802A-56R). However, neither interval exhibits unambiguously the two characteristics that serve to identify reversed magnetization in azimuthally unoriented cores. Moreover, the magnetization behavior is somewhat similar to the peculiar magnetizations observed in Cores $802 \mathrm{~A}-40 \mathrm{R}$ to $802 \mathrm{~A}-44 \mathrm{R}$ ( $358-400 \mathrm{mbsf}$ ), hence it is difficult to determine whether these two short intervals are truly reversed polarity magnetizations or simply the same peculiar magnetization observed at $358-400 \mathrm{mbsf}$. The Coniacian samples exhibit increases in intensity upon demagnetization but the Aptian? sample does not. All three samples exhibit only moderate amounts of directional change $\left(\sim 30^{\circ}\right)$ upon demagnetization; the intensity increases and small directional changes are quite similar to that shown in Figure $10 \mathrm{E}$ from the interval at 358 to $400 \mathrm{mbsf}$. The Santonian samples display steep initial magnetization directions (NRM), suggesting the possibility that the secondary component removed is a drilling remanence. Such incompletely definitive characteristics have been observed in definite reversed intervals elsewhere; however, these characteristics are the same as observed in the region of peculiar magnetization higher in this hole and we are therefore reluctant to interpret this as reversed remanence. Because the possibility of reversed polarity presently cannot be eliminated and because of the increasing reports in the recent literature of possible short reversed events within the Cretaceous Normal Polarity Superchron (e.g., Tarduno, 1990), these short possibly-reversed intervals are indicated in Figure 11.
Paleolatitudes were calculated for each sample in the groups of samples assessed as most reliable (71\%) and slightly less reliable $(18 \%)$ as defined in the discussion of Site 800 . Of the total population of 162 samples, an additional $9 \%$ were unreliable for paleolatitude and $2 \%$ were indeterminate in direction and polarity. The paleolatitudes of the most reliable and somewhat less reliable samples are shown on the left side of Figure 12. These categories are based on magnetization trends to, or close to, the origin during demagnetization. However, significant reasons were presented to doubt the meaning of the magnetization within the interval at $358-400 \mathrm{mbsf}$. Hence, the inclinations of those samples and their implied paleolatitudes are considered unreliable, and are not shown on the right side of Figure 12, which shows only the most reliable paleolatitude values obtained from Site 802 .

Site 802 exhibited a slightly greater number of unreliable samples and somewhat greater dispersion among directions, compared to the other two sites. The differences in both are small, but the peculiar magnetization of the upper volcaniclastic turbidite unit and the hints of it in other parts of the section suggest that the sediments at this site may have preserved a somewhat less accurate record of the remanent magnetization directions than those of the other sites. Additionally, there is poorer preservation of nannofossils at this site than at other sites (Erba, this volume), a fact that strengthens the contention that the remanent magnetization may be less well preserved. Moreover, the record at the other two sites forms essentially continuous smooth curves, unlike Site 802 paleolatitudes, which instead define an irregular, angular tract.

Nevertheless, the paleolatitudes for the Early Tertiary and Late Cretaceous (uppermost portion of the late Campanian and most of the Santonian) agree with those indicated by the other sites. (The positive paleolatitudes observed in the late Campanian and uppermost Santonian, calculated from the samples in the interval of peculiar magnetization between 358 and $400 \mathrm{mbsf}$, are considered unreliable and not shown on the right side of Figure 12.) The mid-Cretaceous (Coniacian and Cenomanian) indicate much shallower paleolatitudes than recorded by Sites 800 and 801 . The few samples of ?late Aptian age are again consistent with paleolatitudes determined at the other sites. The following history of Pacific plate movement is indicated. During Santonian times, the site appears to have been located at about $10^{\circ}$ or greater South latitudes. The uppermost part of the late Campanian record recovered here and the lower part of the recovered Paleocene record indicate that the site had moved to about $4^{\circ} \mathrm{S}$. In early Eocene and ?late Oligocene, the record indicates the site to have been situated at about $4^{\circ} \mathrm{N}$ latitude, and the meager data for the early Miocene seem to suggest an equatorial position, although the most reliable Miocene samples have a slight northern latitudinal bias (Fig. 12 , right column). These samples suggest equatorial crossing of this site in the late Paleocene to early Eocene.

\section{DISCUSSION AND CONCLUSION}

The sedimentary sequences of Leg 129 preserve a paleomagnetic record from which secondary magnetizations were readily removed by demagnetization. The resulting magnetic directions display a clear, coherent record of relatively continuous change in paleolatitude. The magnetic carrier has blocking temperatures below $560^{\circ} \mathrm{C}$, and therefore, probably is a mineral in the titanomagnetite series. One lithology in the sediments from Site 802 indicates the presence of drilling-induced magnetizations, a secondary magnetization generally not observed on this leg.

Much of the sedimentary record represents the time of the Cretaceous Normal Polarity Superchron. The cores of this leg present rather extensive records of that time interval. These were carefully examined for evidence of possible short reversed polarity intervals or events, both because such small episodes have implications for geomagnetic dynamo theory, and because they can occasionally provide valuable stratigraphic marker horizons in an otherwise undistinguished magnetic record. Yet only one of the sites, that with 
the aberrant magnetic behavior seemingly associated with lithology (Site 802), gave any hint of possible short reversed polarity intervals within the long normal interval. Other samples with positive inclinations in Sites 800 and 801 did not display the characteristics of reversed polarity upon demagnetization (increases of intensity or significant directional shifts) and the reasonable possibility that these samples came from pieces of core that had been inverted cannot be eliminated.

The fact that these samples were usually taken individually from small pieces of core, such as the consecutive positive inclination samples (Fig. 3) at $170 \mathrm{~m}$ to $180 \mathrm{~m}$ of Site 800 (Cores $800 \mathrm{~A}-20$, 18-cm-long piece, and 800A-21, 14-cm-long piece), further reinforces the validity of handling errors as the explanation for the positive inclinations. At Site 801, three samples in the top of Core 801B-1 show positive inclinations, but none show any hint of the aforementioned demagnetization characteristics, whereas all samples from this hole with positive inclinations and ages corresponding to times of known reversed polarity do show these demagnetization characteristics. The same is true of the two samples from Core 801B-12, and in this case the core recovery consisted of small fragmentary pieces which could be easily inadvertently inverted. Two possible indications of reversed polarity (suggested by elements of the demagnetization behavior) within Cretaceous Normal Polarity Superchron were found at Site 802; however, there are a number of concerns about the validity of much of the Site 802 data. A portion of the sediments of that hole presented quite abnormal demagnetization behavior. The entire Site 802 data set showed relatively larger dispersion among sample directions than other sites; and the lower part gave demonstrably too-shallow inclinations compared to the other sites. From the extensive Leg 129 magnetostratigraphic records of the Cretaceous Normal Polarity Superchron, and the above considerations of all positive-inclination samples whose ages lie within that time period, it is concluded that no evidence of short reversed polarity intervals or events was observed in these records of the superchron.

The paleolatitude data recorded by these sedimentary records indicate that this oldest portion of the Pacific plate was situated in the Southern Hemisphere from Bathonian-Callovian time through at least the Turonian stage of the Late Cretaceous. The data suggest that Site 801 of the embryonic Pacific plate attained Southern Hemisphere paleolatitudes of nearly $20^{\circ} \mathrm{S}$, maximum southern latitudes being achieved in middle Albian through early Aptian time. The segment of the plate containing the three sites probably moved into the Northern Hemisphere during the time interval of Turonian (Site 800) through the Late Paleocene (Site 802).

Inclination error may well be present in these data if the studies of Tarduno (1990) and Gordon (1990) are any indication. According to Tarduno's (1990) study, the error expected for the maximum inclinations of this study (Sites $800-801$ ) is about $18^{\circ}$, implying a maximum original inclination of $51^{\circ}$, and hence a paleolatitude of $32^{\circ}$ for the vicinity of Sites $800-801$. However, the maximum predicted paleolatitudes from this region, derived from a combination of seamount paleopoles (Sager and Pringle, 1988) and magnetic anomaly skewness (Larson and Sager, this volume) is about $23^{\circ}$.

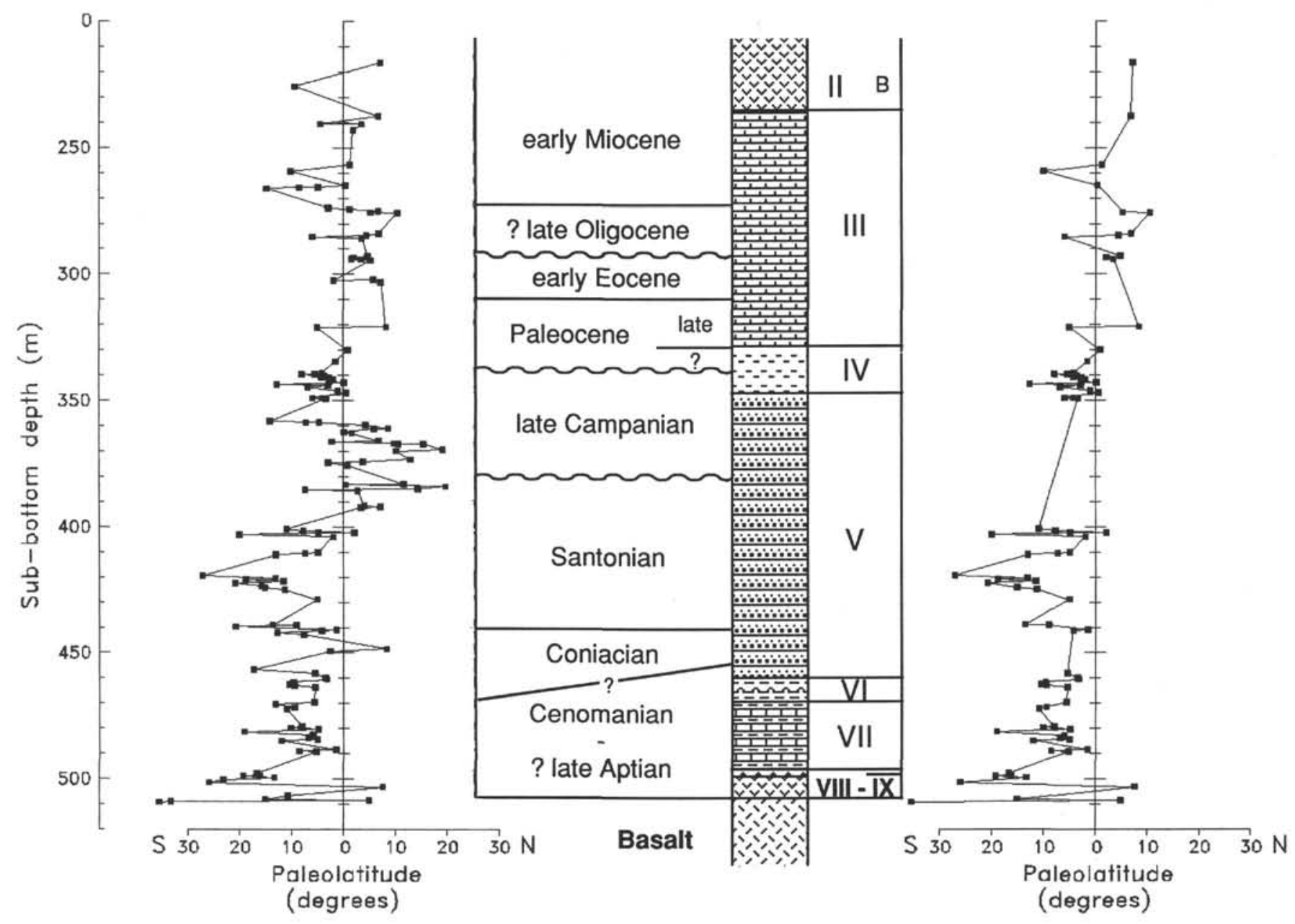

Figure 12. Site 802. Stratigraphic plot of paleolatitude calculated for each sample of the most reliable and slightly less reliable categories (see text, Site 800) in left plot; right plot displays only the most reliable samples. Ages and lithologies from Shipboard Scientific Party (1990c). 
Moreover, nannofossil abundances predict paleolatitudes for the Aptian through Cenomanian that are in excellent agreement with those derived here from sediment inclinations (Erba, this volume). Predictions from nannofossil abundances assume that the present upwelling zones were the same in the Cretaceous as they are today. Therefore, to ignore this agreement with sediment paleolatitudes implies that the upwelling zones were much broader than at present. That may well be, but the "igneous rock" predictions of paleolatitude are still much less than expected if inclination error is present in the sediments and is present in the amount predicted either by the inclination error-latitude relationship derived by Tarduno (1990) or that indicated by Gordon (1990).

The Pacific plate motion history suggested by the paleolatitudinal data of this study is one in which the embryonic portion of the Pacific plate resided slightly south of the magnetic equator in the Middle and Late Jurassic and Early Cretaceous and moved to more southerly latitudes of probably $20^{\circ} \mathrm{S}$ or more by Aptian time. The plate appears to have remained at those high southern latitudes through the mid-Albian (perhaps drifting very slightly to the north), and then moved northward to low southerly latitudes by the Late Cretaceous (Cenomanian to Campanian-Maestrichtian). The data for the southern portion of this embryonic plate (Site 802) suggests equatorial to low northerly latitudes during the late Paleocene through early Miocene.

\section{REFERENCES}

Gordon, R. G., 1990. Test for bias in paleomagnetically determined paleolatitudes from Pacific Plate Deep Sea Drilling Project sediments. J. Geophys. Res., 95:8397-8404.

Haq, B. U., Hardenbol J., and Vail, P. R., 1988. Mesozoic and Cenozoic chronostratigraphy and cycles of sea-level change. In Wilgus, C. K., Hastings, B. S., Kendall, C.G.St.C., Posamentier, H. W., Ross, C. A., and Van Wagoner, J. C. (Eds.), Sea-Level Changes: An Integrated Approach. Spec. Publ.-Soc. Econ. Paleontol. Mineral., 42:71-108.

Harland, W. B., Armstrong, R. L., Cox, A. V., Craig, L. E., Smith, A. G., and Smith, D. G., 1989. A Geologic Time Scale 1989: Cambridge (Cambridge Univ. Press).
Kirschvink, J. L., 1980. The least-squares line and plane and the analysis of paleomagnetic data. Geophys. J., 62:699-718.

Larson, R. L., and Hilde, T.W.C., 1975. A revised time scale of magnetic reversals for the Early Cretaceous and Late Jurassic. J. Geophys. Res., 80:2586-2594.

Ogg, J. G., 1987. Early Cretaceous magnetic polarity time scale and the magnetostratigraphy of Deep Sea Drilling Project Sites 603 and 534, western Central Atlantic: DSDP Leg 93. In van Hinte, J. E., Wise, S. W., Jr., et al., Init. Repts. DSDP, 93: Washington (U.S. Govt. Printing Office), 849-879.

Ogg, J. G., Steiner, M. B., Company, M., and Tavera, J. M., 1988. Magnetostratigraphy Across the Berriasian-Valanginian Stage Boundary (Early Cretaceous), at Cehegin (Murcia Province, southern Spain), Earth Planet. Sci. Lett., 87:205-215.

Sager, W. W., and Pringle, M. S., 1988. Mid-Cretaceous to Early Tertiary apparent polar wander path of the Pacific Plate. J. Geophys. Res., 93:11753-11771.

Shipboard Scientific Party, 1990a. Site 800. In Lancelot, Y., and Larson, R. L., et al., Proc. ODP, Init. Repts., 129: College Station, TX (Ocean Drilling Program), 33-89.

, 1990b. Site 801. In Lancelot, Y., and Larson, R. L., et al., Proc. ODP, Init. Repts., 129: College Station, TX (Ocean Drilling Program), 91-170.

, 1990c. Site 802. In Lancelot, Y., and Larson, R. L., et al., Proc. ODP, Init. Repts., 129: College Station, TX (Ocean Drilling Program), $171-243$.

Steiner, M. B., and Ogg, J. G., 1988. Early and Middle Jurassic Polarity Timescale. In Rocha, R. B., and Soares, A. F. (Eds.), 2nd Int. Symp. Jurassic Stratigraphy (Lisboa, 1987) (Vol. 2). Cent. de Estratigr. da Univ. de Coimbra (INIC), Lisbon, 1097-1111.

Tarduno, J. A., 1990a. Brief reversed polarity interval during the Cretaceous Normal Polarity Superchron. Geology, 18:683-686.

1990b. Absolute inclination values from deep sea sediments: a reexamination of the Cretaceous Pacific record. Geophys. Res. Lett., 17:101-104.

Date of initial receipt: 3 June 1991

Date of acceptance: 13 March 1992

Ms 129B-136 